\title{
Assimilation of satellite-derived skin temperature observations into land surface models
}

\author{
Rolf H. Reichle ${ }^{1}$, Sujay V. Kumar ${ }^{2,3}$, Sarith P. P. Mahanama ${ }^{1,4}$, \\ Randal D. Koster ${ }^{1}$ and Q. Liu ${ }^{1,2}$
}

\section{Manuscript submitted to Journal of Hydrometeorology}

$$
19 \text { January 2010, 2:07 PM }
$$

1 Global Modeling and Assimilation Office NASA Goddard Space Flight Center Greenbelt, MD, USA

2 Science Applications International Corporation Beltsville, MD, USA

3 Hydrological Sciences Branch NASA Goddard Space Flight Center Greenbelt, MD, USA

$4 \quad$ Goddard Earth Sciences and Technology Center University of Maryland, Baltimore County Baltimore, MD, USA

\section{Corresponding author address}

Rolf H. Reichle

NASA Goddard Space Flight Center

Mail Code 610.1

8800 Greenbelt Road

Greenbelt, MD 20771

USA

Tel.:

301-614-5693

FAX:

301-614-6297

Email:

rolf.reichle@nasa.gov 


\section{Abstract}

3 Land surface (or "skin") temperature (LST) lies at the heart of the surface energy balance and is a

4 key variable in weather and climate models. Here we assimilate LST retrievals from the

5 International Satellite Cloud Climatology Project (ISCCP) into the Noah and Catchment (CLSM)

6 land surface models using an ensemble-based, off-line land data assimilation system. LST is

7 described very differently in the two models. A priori scaling and dynamic bias estimation

8 approaches are applied because satellite and model LST typically exhibit different mean values

9 and variability. Performance is measured against 27 months of in situ measurements from the

10 Coordinated Energy and Water Cycle Observations Project at 48 stations. LST estimates from

11 Noah and CLSM without data assimilation ("open loop") are comparable to each other and

12 superior to that of ISCCP retrievals. For LST, RMSE values are 4.9 K (CLSM), 5.6 K (Noah),

13 and 7.6 K (ISCCP), and anomaly correlation coefficients (R) are 0.62 (CLSM), 0.61 (Noah), and

140.52 (ISCCP). Assimilation of ISCCP retrievals provides modest yet statistically significant

15 improvements (over open loop) of up to $0.7 \mathrm{~K}$ in RMSE and 0.05 in anomaly R. The skill of

16 surface turbulent flux estimates from the assimilation integrations is essentially identical to the

17 corresponding open loop skill. Noah assimilation estimates of ground heat flux, however, can be

18 significantly worse than open loop estimates. Provided the assimilation system is properly

19 adapted to each land model, the benefits from the assimilation of LST retrievals are comparable

20 for both models. 


\section{1. Introduction}

23 Land surface conditions are intimately connected with the global climate system and have been

24 associated, through different pathways, with atmospheric predictability. Land surface

25 temperature (LST) lies at the heart of the surface energy balance and is therefore a key variable

26 in weather and climate models. LST influences the latent and sensible heat fluxes to the

27 atmosphere through which it affects the planetary boundary layer and atmospheric convection.

28 LST also plays an important role in the assimilation of atmospheric remote sensing observations

29 because atmospheric retrieval algorithms (or forward radiative transfer modeling) for surface-

30 sensitive (window) channels require information about land surface conditions. Accurate LST

31 specification is therefore critical to improving estimates of the surface water, energy, and

32 radiation balance as well as atmospheric quantities, which in turn are all critical to improving

33 weather and climate forecast accuracy.

35 Satellite retrievals of LST (also referred to as "skin temperature") are available from a variety of 36 polar orbiting and geostationary platforms carrying infrared and microwave sensors (Aires et al.

37 2004, Jin 2004, Minnis and Khaiyer 2000, Pinheiro et al. 2004, Rossow and Schiffer 1991, 1999,

38 Trigo and Viterbo 2003, Wan and Li 1997). Land surface models (driven by observed

39 meteorological forcing data or coupled to an atmospheric model) offer estimates of global land

40 surface conditions, including LST. Errors in the forcing fields, however, along with the

41 imperfect parameterization of land-atmosphere interactions can lead to considerable drifts in

42 modeled land surface states. Land data assimilation systems combine the complementary

43 information from modeled and observed land surface fields and produce dynamically consistent,

44 spatially complete and temporally continuous estimates of global land surface conditions. 
45 Assimilating LST retrievals into a land surface model should, in concept, improve model

46 estimates of land surface conditions.

48 There has been considerable progress in the methodological development and application of land

49 data assimilation algorithms (Andreadis and Lettenmaier 2005, Balsamo et al. 2007, Crow and

50 Wood 2003, Drusch 2007, Dunne and Entekhabi 2006, Mahfouf et al. 2009, Margulis et al. 2002,

51 Pan and Wood 2006, Reichle et al. 2009, Seuffert et al. 2003, Slater and Clark 2006, Walker et

52 al. 2001, Zaitchik and Rodell 2009, Zhou et al. 2006), with ensemble-based Kalman filtering and

53 smoothing algorithms emerging as a common and promising method for land data assimilation.

54 Development and applications of land data assimilation, however, have largely focused on

55 assimilating observations of surface soil moisture, snow cover, and snow water equivalent, with

56 less effort devoted to LST assimilation.

58 The goal of this study is to investigate the potential for assimilating satellite retrievals of LST

59 within a state-of-the-art land surface data assimilation system. Specifically, LST retrievals from

60 the International Satellite Cloud Climatology Project (ISCCP) are assimilated into the NASA

61 Catchment land surface model (CLSM; Koster et al. 2000) and into the Noah land surface model

62 (Ek et al. 2003) with the ensemble Kalman filter (EnKF) developed at the NASA Global

63 Modeling and Assimilation Office (Reichle et al. 2009). For validation of the assimilation

64 products we use in situ observations from the Coordinated Energy and Water Cycle Observations

65 Project (CEOP). We pay particular attention to bias between observed and modeled LST and

66 have fitted the EnKF with several bias estimation algorithms designed specifically to address

67 LST biases. It will be shown that the assimilation algorithm must be customized for the model-

68 specific representation of LST. 


\section{Background}

70 LST can be retrieved from infrared and microwave sensors on geostationary and polar-orbiting

71 platforms, including the NOAA Geostationary and Polar-orbiting Operational Environmental

72 Satellite series dating back to the early 1980's. Given the extensive global and multi-decadal

73 record of satellite-based LST retrievals, and given the importance of accurate LST estimation in

74 particular for global atmospheric data assimilation systems, it is telling that the challenge of

75 operational LST assimilation has been largely unmet.

77 The difficulties of LST data assimilation are rooted in the nature of LST retrievals and modeling.

78 LST data from retrievals and land surface models typically exhibit strong biases that depend on

79 observation time and location and that have been well documented (see, for instance, Jin et al.

80 1997, Trigo and Viterbo 2003, Jin 2004; see also section 6 for examples). Biases arise for a

81 variety of reasons. For instance, LST modeling is fraught with numerical stability problems

82 because in nature the effective heat capacity associated with LST is very small. Land modelers

83 are thus forced to approximate the corresponding heat capacity as zero or to use a surface

84 temperature prognostic variable that represents more than just a very thin layer. The first

85 approach, used for example in Noah, derives LST as a diagnostic variable from the surface

86 energy balance. The second approach, used for example in CLSM, lumps the vegetation and top

87 few centimeters of soil matter into a single model prognostic variable with a small but non-zero

88 heat capacity. The latter approach is obviously at odds with satellite retrievals of LST, which

89 describe the temperature in a much shallower layer at the land-atmosphere interface (vegetation

90 or soil, as viewed from the satellite sensor). On the other hand, the zero-heat capacity approach

91 requires an additional connection between the diagnostic model LST variable and a model 
92 prognostic variable to which data assimilation increments can be applied (so that they can alter

93 the model forecast). Additional discrepancies between the LST observed by the satellite and that

94 computed by the land model stem from the inability of global land models to resolve the land

95 surface at the same fine horizontal resolution as infrared satellite sensors.

97 Satellite-based LST retrievals suffer from their own set of disadvantages and problems. Infrared

98 LST retrievals are only available under clear-sky conditions and are notoriously prone to cloud

99 contamination (Jin 2004). Microwave LST retrievals are available under cloudy conditions

100 (Aires et al. 2004) but depend on uncertain estimates of microwave land surface emissivity.

101 Both infrared and microwave LST retrievals depend on knowledge of atmospheric conditions

102 above the LST footprint. LST retrievals also depend on the look-angle, which is particularly

103 important for retrievals at high viewing angles (Minnis and Khaiyer 2000, Pinheiro et al. 2004).

104 The benefit of having a great variety and long record of different platforms from which LST can

105 be retrieved is partly negated by the corresponding variety of sensor characteristics and sensor-

106 specific LST retrieval algorithms that make it difficult to achieve a homogeneous satellite LST

107 record.

108

109 Additional complications arise when model and satellite LST are combined in a data assimilation

110 system. The strong seasonal and diurnal cycles of LST must be considered because error

111 characteristics may depend on time-of-day and season. Moreover, obvious problems result when

112 (clear-sky) LST retrievals are assimilated into a model at a time and location for which the model

113 state or forcing indicate cloudy conditions. Because the infrared and microwave emissivities of

114 the land surface are not well known, it is difficult to compare the radiometric temperature 
115 observed by the satellite with the physical temperature of the land model. Last but not least, the

116 dearth of validating in situ observations of LST and land surface fluxes is a severe impediment to

117 the validation of data products from satellite observations, modeling, and data assimilation.

119 One major development path is to assimilate LST retrievals into a simple representation of the 120 land surface energy balance using an adjoint-based variational assimilation approach (Castelli et 121 al. 1999; Boni et al. 2001; Caparrini et al. 2004; Sini et al. 2008). This elegant method requires

122 only a minimal amount of ancillary data and provides robust estimates of evaporative fraction. It

123 is not, however, easily applicable to existing global atmospheric or land data assimilation

124 systems because it is very difficult to develop and maintain adjoint models for the complex land

125 surface model components in such systems. Recently, Meng et al. (2009) developed the adjoint 126 model of just the surface energy balance component of the Common Land Model. Using the 127 variational method, the authors assimilated in situ LST observations from four AmeriFlux sites

128 for up to 20 days and report improvements in evapotranspiration estimates when verified against 129 coincident in situ observations.

131 Other off-line surface temperature assimilation studies used filtering techniques. Kumar and 132 Kaleita (2003) used the Extended Kalman filter to assimilate in situ observations of surface soil 133 temperature from a single site for one month into a soil heat transfer model based on the 134 discretized diffusion equation. Lakshmi (2000) merged one year of satellite retrievals of LST 135 over the Red-Arkansas basin into a simple two-layer model of the surface water and energy 136 balance. 
138 A few attempts have been made to adjust terms in the surface energy balance of atmospheric

139 models in response to satellite LST retrievals. McNider et al. (1994) describe a technique to

140 assimilate satellite LST into the surface energy budget of a regional-scale atmospheric model.

141 Their method assumes that surface soil moisture is the least known parameter in the early-

142 morning surface energy budget. Van den Hurk et al. (2002) assimilated satellite LST and near-

143 surface relative humidity measurements into a regional weather forecast model. By adjusting the

144 root zone soil moisture and the roughness length for heat the authors find small improvements in

145 the surface energy balance. Garand (2003) outlines a variational method for a unified land and

146 ocean surface skin temperature analysis, including a linear a priori bias correction of the

147 assimilated radiances.

149 Bosilovich et al. (2007) developed an algorithm for LST assimilation into a global model that

150 introduces an incremental bias correction term into the model's surface energy budget. In

151 contrast to the McNider et al. (1994) approach, all temperature-dependent terms in the surface

152 energy budget respond directly to the LST retrievals. In its simplest form, the Bosilovich et al.

153 (2007) algorithm estimates and corrects a constant time mean bias for each grid point; additional

154 benefits are attained with a refined version of the algorithm that allows for a correction of the

155 mean diurnal cycle. The results of Bosilovich et al. (2007) indicate that LST assimilation

156 improves estimates of $2 \mathrm{~m}$ air temperature, both in mean and variability, in a coupled land-

157 atmosphere model. Neglecting the diurnal cycle of the LST bias causes degradation of the

158 diurnal amplitude of background model air temperature in many regions. In situ measurements

159 of energy fluxes at several locations were used to inspect the surface energy budget more closely.

160 LST assimilation generally improves the sensible heat flux and, in some cases, it improves the 
161 Bowen ratio. At many stations, however, LST assimilation increases slightly the bias in the

162 monthly latent heat flux. A critical limitation of the method of Bosilovich et al. (2007) is the 163 assumption of unbiased LST retrievals.

164

165 In this paper, we restrict ourselves to uncoupled land data assimilation and test several variants

166 of the bias estimation strategy of Bosilovich et al. (2007). We also explore an alternative

167 strategy of scaling the LST retrievals into the climatology of the modeled LST. As we will show

168 in section 6, not scaling the LST retrievals prior to (uncoupled land) data assimilation can create

169 serious imbalances in the model-generated mass and energy fluxes and can lead to entirely

170 unrealistic land surface fluxes. We test these approaches with two land surface models that

171 represent LST very differently: CLSM and Noah (section 4). Our results are directly linked to

172 weather and climate prediction applications because these two land models are used in the

173 atmospheric data assimilation systems of the NASA Global Modeling and Assimilation Office

174 (GMAO) and the NOAA National Centers for Environmental Prediction (NCEP), respectively. 
177 In this study, we assimilate LST retrievals from ISCCP (http://isccp.giss.nasa.gov; Rossow and

178 Schiffer 1991, 1999). The ISCCP archive contains satellite-based estimates of global cloud

179 cover and radiative properties from 1983 through the present (recent data are added with a

180 latency of about 1 year), and is based on observations from an international network of

181 meteorological satellites. Specifically, the ISCCP $30 \mathrm{~km}$ Pixel Level Cloud Product (DX)

182 includes global, 3-hourly, clear-sky LST retrievals from infrared radiances. For this study, we

183 extracted LST retrievals from the DX archive for the geostationary platforms and aggregated the

184 data to a global latitude-longitude grid with 1 degree resolution for assimilation into our system.

186 The availability of validating land surface temperature and flux data is very limited. In this

187 study, we use the comparably large collection of such data provided by CEOP

188 (http://www.ceop.net) to validate the data assimilation products. Specifically, we obtained

189 hourly data from the network of CEOP Reference Sites from 1 October 2002 through 31

190 December 2004 (Figure 1, Table 1). Sufficient data for validation are available at 48 distinct

191 sites, of which 19 sites have LST data, 30 have latent heat (LH) and sensible heat (SH) flux data,

192 and 20 sites have ground heat (GH) flux data. Only 4 stations have LST as well as LH, SH, and

193 GH observations sufficient for validation (Cabauw, Bondville, Lindenberg Falkenberg, and

194 Lindenberg Forest). The hourly CEOP data were aggregated to 3-hourly averages for

195 comparison with the 3-hourly retrieval, model, and assimilation products.

196

197 The surface meteorological forcing data for the two land models are from the Global Land Data

198 Assimilation Systems (GLDAS) project (Rodell et al. 2003; http://ldas.gsfc.nasa.gov) and were 
199 provided at 3-hourly time steps and at $2^{\circ}$ and $2.5^{\circ}$ resolution in latitude and longitude, 200 respectively. The GLDAS data stream is based on output from the global atmospheric data 201 assimilation system at the NASA Global Modeling and Assimilation Office (Bloom et al. 2005)

202 adjusted with pentad precipitation observations from the Climate Prediction Center Merged 203 Analysis of Precipitation (CMAP; http://www.cdc.noaa.gov/cdc/data.cmap.html) and daily 204 estimates of surface radiation from the Air Force Weather Agency (AFWA) Agricultural 205 Meteorology (AGRMET) system. The observation-based corrections ensure that the forcing data 206 and hence the land model output are as close to reality as is possible (without the benefit of 207 assimilating the LST retrievals).

208 


\section{Data assimilation system}

\section{4.a. The Catchment and Noah land surface models}

211 Modeled LST and land surface fluxes are from integrations of CLSM (Koster et al. 2000) and

212 Noah (Ek et al. 2003). Again, these two models are the land model components of the

213 atmospheric data assimilation and forecasting systems at NASA GMAO and NOAA NCEP,

214 respectively. Both models dynamically predict land surface water and energy fluxes in response

215 to surface meteorological forcing but follow markedly different approaches to modeling soil

216 moisture and LST.

217

218 CLSM's basic computational unit is the hydrological catchment (or watershed). The global land

219 surface is divided into catchments (excluding inland water and ice-covered areas) with a mean

220 linear scale of around $50 \mathrm{~km}$ (ranging from a few $\mathrm{km}$ to $250 \mathrm{~km}$ ). Unlike traditional, layer-based

221 models, CLSM includes an explicit treatment of the spatial variation of soil water and water table

222 depth within each hydrological catchment based on the statistics of the catchment topography.

223 The surface energy balance is computed separately for the (dynamically varying) saturated,

224 transpiring, and wilting sub-areas of each catchment. In each of these three sub-areas, the bulk

225 temperature of the vegetation canopy and the top $5 \mathrm{~cm}$ of the soil column is modeled with a

226 "surface temperature" (TSURF) prognostic variable that is specific to the soil moisture regime.

227 The three TSURF prognostic variables interact with an underlying heat diffusion model for soil

228 temperature (consisting of six layers with depths equal to about 10, 20, 40, 75, 150, $1000 \mathrm{~cm}$

229 from top to bottom) that is common to the three sub-areas (see Figure 5 of Koster et al. 2000). In

230 the absence of snow, the area-weighted average of the three prognostic TSURF variables

231 (hereinafter also referred to as the "surface temperature" in CLSM) is the most appropriate 
232 quantity to compare to satellite-based LST retrievals (Figure 2). CLSM integrations were

233 conducted using the GMAO land data assimilation system (Reichle et al. 2009) with a model

234 time step of 20 minutes.

235

236 Noah is a more traditional, layer-based model. Four soil layers of increasing thicknesses of 10,

23730,60 and $100 \mathrm{~cm}$ are used to model soil temperature and moisture dynamics with layer-based

238 formulations of the heat diffusion equation (for energy) and of the standard diffusion and gravity

239 drainage equations (for unsaturated water flow). LST in Noah is diagnosed from the surface

240 energy balance equation and, unlike in CLSM, is not a prognostic variable and has no associated

241 heat capacity (Figure 2). In this study, we use Noah version 2.7.1 on a 0.5 degree grid with a 30

242 minute time step. Noah integrations were carried out with the Land Information System (Kumar

243 et al. 2008) fitted with the GMAO ensemble data assimilation and bias estimation modules

244 (Reichle et al. 2009).

245

246 4.b. Data assimilation method and parameters

247 In a data assimilation system, the model-generated land surface estimates are corrected toward

248 observational estimates, with the degree of correction determined by the levels of error

249 associated with each. The assimilation system used here is based on the Ensemble Kalman filter

250 (EnKF), which is well suited to the non-linear and intermittent character of land surface

251 processes (Reichle et al. 2002a, 2002b). The EnKF works sequentially by performing in turn a

252 model forecast step and a filter update step. Formally, the forecast step for ensemble member i

253 can be written as

254 


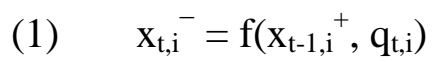

256

257 where $\mathrm{x}_{\mathrm{t}, \mathrm{i}}{ }^{-}$and $\mathrm{x}_{\mathrm{t}-1, \mathrm{i}}{ }^{+}$are the forecast (denoted with ${ }^{-}$) and analysis (denoted with $^{+}$) state vectors

258 at times $t$ and $\mathrm{t}-1$, respectively. The model error (or perturbation vector) is denoted with $\mathrm{q}_{\mathrm{t}, \mathrm{i}}$ and

259 its covariance with $\mathrm{Q}_{\mathrm{t}}$. The filter update produces the analyzed state vector $\mathrm{x}_{\mathrm{t}, \mathrm{i}}{ }^{+}$at time $\mathrm{t}$ and can

260 be written as

261

262

(2) $\quad \mathrm{x}_{\mathrm{t}, \mathrm{i}}^{+}=\mathrm{x}_{\mathrm{t}, \mathrm{i}}^{-}+\mathrm{K}_{\mathrm{x}, \mathrm{t}}\left(\mathrm{y}_{\mathrm{t}, \mathrm{i}}-\mathrm{H}_{\mathrm{t}} \mathrm{x}_{\mathrm{t}, \mathrm{i}}^{-}\right)$

263

264 where $\mathrm{y}_{\mathrm{t}, \mathrm{i}}$ denotes the observation vector (suitably perturbed) and $\mathrm{H}_{\mathrm{t}}$ is the observation operator

265 (which is written as if it were linear for ease of notation, but in practice the update is solved

266 without explicitly computing $\mathrm{H}_{\mathrm{t}}$; Keppenne et al. 2000). The Kalman gain matrix $\mathrm{K}_{\mathrm{x}, \mathrm{t}}$ is given by

(3) $\quad \mathrm{K}_{\mathrm{x}, \mathrm{t}}=\mathrm{P}_{\mathrm{x}, \mathrm{t}} \mathrm{H}_{\mathrm{t}}^{\mathrm{T}}\left(\mathrm{H}_{\mathrm{t}} \mathrm{P}_{\mathrm{x}, \mathrm{t}} \mathrm{H}_{\mathrm{t}}^{\mathrm{T}}+\mathrm{R}_{\mathrm{t}}\right)^{-1}$

269

270 where $P_{x, t}$ is the state forecast error covariance (diagnosed from the ensemble $x_{t, i}{ }^{-}$), $R_{t}$ is the

271 observation error covariance, and superscript T denotes the matrix transpose. Simply put, the

272 Kalman gain $\mathrm{K}_{\mathrm{x}, \mathrm{t}}$ represents the relative weights given to the model forecast and the

273 observations, based on their respective uncertainties and based on the error correlations between

274 the elements of the state vector and the model prediction of the observed variable. In this paper,

275 we use 12 ensemble members with a "one-dimensional" (1d) EnKF that processes each location

276 independently of all other locations (see, for example, Reichle and Koster (2003) for 1d versus 
3d assimilation). The key feature of the EnKF is that error estimates of the model-generated results are dynamically derived from an ensemble of non-linear model integrations.

Perturbation fields were generated and applied to surface air temperature and radiation which represent the dominant forcing inputs for LST. Perturbations were also applied to model prognostic variables (the Catchment surface temperature TSURF and the Noah top layer soil temperature TSOIL1), reflecting errors in the modeling of the surface energy balance.

Collectively, the perturbations allow us to maintain an ensemble of land surface conditions that represents the uncertainty in modeled LST. An overview of the perturbation parameters is given in Table 2. Depending on the variable, normally distributed additive perturbations or lognormally distributed multiplicative perturbations were applied. The ensemble mean for all perturbations was constrained to zero for additive perturbations and to one for multiplicative perturbations. Moreover, time series correlations were imposed via a first-order auto-regressive model (AR(1)) for all fields. Since we used a one-dimensional EnKF in this study, the perturbation fields were not spatially correlated. At hourly and daily time scales, the meteorological forcing fields are ultimately based on output from atmospheric modeling and analysis systems and not on direct observations of surface forcings. We imposed error crosscorrelations that are motivated by the assumption that the atmospheric forcing fields represent a realistic balance between radiation, clouds, and air temperature. Under that assumption, for example, a positive perturbation to the downward shortwave radiation tends to be associated with negative perturbations to the longwave radiation and with a positive perturbation to air temperature. 
Model errors are difficult to quantify at the global scale. The parameter values listed in Table 2

301 are largely based on experience and are partially supported by earlier studies (Reichle et al.

302 2002b; Reichle and Koster 2003; Reichle et al. 2007). The success of the assimilation presented

303 here (section 6) suggests that these values are acceptable. In any case, further calibration of the

304 filter parameters would, in theory, only improve the assimilation results. Clearly, more research

305 is needed on the exact nature of the model and forcing errors. Recently developed adaptive

306 filtering methods for land assimilation may assist with error parameter estimation (Reichle et al.

307 2008, Crow and Reichle 2008).

308

309 The mapping of the satellite information from the observation space into the space of the model

310 states is accomplished through the Kalman gain during the EnKF update step. Equation (2)

311 linearly relates "innovations" (observations minus corresponding model estimates before EnKF

312 update, that is, $\mathrm{y}_{\mathrm{t}, \mathrm{i}}-\mathrm{H}_{\mathrm{t}} \mathrm{x}_{\mathrm{t}, \mathrm{i}}{ }^{-}$) to "increments" (model states after EnKF update minus same before

313 EnKF update, that is, $\mathrm{x}_{\mathrm{t}, \mathrm{i}^{+}}{ }^{-} \mathrm{x}_{\mathrm{t}, \mathrm{i}}^{-}$). In this study, we use CLSM's area-average TSURF variable

314 and Noah's diagnostic TSKIN variable to compute the (observation-space) innovations (Figure 2

315 and Section 4a). The EnKF state vector for CLSM consists of the three TSURF prognostic

316 variables (specific to each soil moisture regime, section 4a), while the EnKF state vector for

317 Noah consists of the top layer soil temperature TSOIL1. The key ingredients to the Kalman gain

318 are the error correlations between the LST variables in observation space and the EnKF state

319 variables (Reichle et al. 2002b). For Noah, the relevant error correlation is between the

320 diagnostic TSKIN variable (that has no associated heat capacity) and the temperature in the top

$32110 \mathrm{~cm}$ soil layer. Therefore, in the case of Noah the error correlation is affected by a small phase

322 shift between the diurnal cycle of the diagnostic TSKIN and the top layer soil temperature 
323 TSOIL1. Observations are not assimilated when precipitation is falling or when the ground is

324 covered with snow (as indicated by the land model integration).

325

\section{4.c. Bias estimation}

327 For the reasons outlined in section 2 there are considerable differences between the temporal 328 moments of the satellite and model LST (see section 6 for examples). Such biases need to be 329 addressed in the data assimilation system. For this study, we implemented two different

330 strategies. The first strategy is to scale the satellite observations to the model's climatology so

331 that the first and second moments of the satellite LST and the model LST match. This strategy is

332 a simplified version of the cumulative distribution function matching (Reichle and Koster 2004)

333 that has been used successfully for soil moisture assimilation (Reichle et al. 2009). Because of

334 the strong diurnal and seasonal cycles of LST, we estimated the multi-year LST mean and

335 variance separately for each calendar month and for eight different times-of-day $(0 z, 3 z, \ldots$,

336 21z). This strategy is very easy to implement through preprocessing of the LST retrievals and

337 makes no assumptions regarding whether the model's or the observations' climatology is more

338 correct. Although the assimilation estimates are by design produced in the model's climatology,

339 they could be scaled back to the observational climatology if desired. The scaling strategy can

340 be applied to the assimilation of retrievals from a variety of satellite datasets with different

341 climatologies. An obvious disadvantage is the fact that the a priori scaling is static and cannot

342 automatically adjust to dynamic changes in bias.

344 The second strategy is to dynamically estimate bias parameters along the lines of the algorithm

345 developed by Dee (2005), which was used for LST by Bosilovich et al. (2007) and for soil 
moisture by De Lannoy et al. (2007). This dynamic bias estimation approach is based on a second Kalman filter for bias estimation (in addition to the Kalman filter for state estimation).

348 Assume that we have a bias estimate $\mathrm{b}_{\mathrm{t}-1}{ }^{+}$at time $\mathrm{t}-1$. Furthermore, assume that this bias

349 estimate can be propagated to time t with a simple bias evolution model

350

351

(4) $\quad b_{t}^{-}=\alpha b_{t-1}^{+}$

352

353 that relaxes the bias estimates to zero $(0<\alpha<1)$. In our experiments, we chose $\alpha$ to correspond

354 to an e-folding scale of 1 day. The use of a relaxation factor is different from the implementation

355 of Bosilovich et al. (2007) and is a prudent strategy for experiments that cover many seasons.

356 Because observations may not be available for extended periods, relaxing the bias estimate to

357 zero is safer than keeping the latest bias estimate through seasons for which it may not be

358 appropriate.

359

360 Next, we compute a bias-corrected model forecast

361

362

(5) $\quad \xi_{\mathrm{t}, \mathrm{i}}^{-}=\mathrm{x}_{\mathrm{t}, \mathrm{i}}^{-}-\mathrm{b}_{\mathrm{t}}^{-}$

363

364 that is used in the state update equation (2) (instead of the biased model forecast $\mathrm{x}_{\mathrm{t}, \mathrm{i}}{ }^{-}$). From

365 ensemble average innovations (computed as $\mathrm{y}_{\mathrm{t}}-\mathrm{H}_{\mathrm{t}} \xi_{\mathrm{t}}^{-} \equiv \mathrm{E}\left\{\mathrm{y}_{\mathrm{t}, \mathrm{i}}-\mathrm{H}_{\mathrm{t}} \xi_{\mathrm{t}, \mathrm{i}}{ }^{-}\right\}$, where $\mathrm{E}\{\cdot\}$ is the

366 ensemble mean operator), we can then update the bias via

367

368

(6) $\quad \mathrm{b}_{\mathrm{t}}^{+}=\mathrm{b}_{\mathrm{t}}^{-}-\gamma \mathrm{K}_{\mathrm{x}, \mathrm{t}}\left(\mathrm{y}_{\mathrm{t}}-\mathrm{H}_{\mathrm{t}} \xi_{\mathrm{t}}^{-}\right)$ 
370 A key assumption of this algorithm is that the bias error covariance $\mathrm{P}_{\mathrm{b}, \mathrm{t}}$ is a small fraction of the

371 state error covariance, that is $\mathrm{P}_{\mathrm{b}, \mathrm{t}}=\gamma \mathrm{P}_{\mathrm{x}, \mathrm{t}}$, which implies that the gain for the bias ( $\left.\mathrm{K}_{\mathrm{b}, \mathrm{t}}\right)$ can be

372 computed as a fraction of the gain for the state, which has already been computed. Here, we use

$373 \gamma=0.2$ for Catchment and $\gamma=0.05$ for Noah. The difference in $\gamma$ is motivated by the different

374 surface layer thicknesses in the two models, but like the perturbations parameters that govern the 375 model error, these bias parameters have not been optimized and are justified primarily by the 376 success of the assimilation.

378 As formulated above, the bias algorithm estimates a single bias parameter (per state and per

379 location). Here, we implemented a variant that estimates a separate bias parameter for eight

380 different times-of-day $(0 z, 3 z, \ldots, 21 z)$. Because this requires the estimation of eight bias

381 parameters per state and per location, we refer to this algorithm as "b8". Additional variants of

382 the dynamic bias algorithm are discussed in the appendix.

384 Equation (6) implies that in practice, the bias estimates can be thought of as an exponential 385 moving (time) average of the LST increments. Unlike the scaling approach, the dynamic bias 386 estimation strategy adapts to slow changes in bias over time. A major disadvantage of this 387 strategy is the implicit assumption that only the model is biased, which contradicts previous 388 findings that retrievals from different sensors may be biased against each other (for example, 389 Trigo and Viterbo 2003). It is therefore critical that any bias between retrievals from different 390 sensors is small compared to the bias between retrievals and the model estimates. 
392 For this study we implemented the a priori scaling method and the dynamic bias estimation 393 schemes independently. The latter can be invoked with and without a priori scaling. If invoked 394 without a priori scaling, the dynamic bias estimation corrects for static (long-term) biases as well 395 as shorter-term "bias" that results from transient differences between model and observational 396 estimates. If invoked after a priori scaling, the dynamic bias estimation mostly corrects for 397 transient bias. It can also be considered a tool for remembering assimilation increments that 398 would otherwise be forgotten within a single model time step (because of the small heat capacity 399 associated with LST). This is particularly important for CLSM as section 6 will show.

400 


\section{Experiment design and skill metrics}

402 The experiment domain consists of the catchments (or grid cells) that contain the CEOP station

403 locations (Figure 1). The land models were spun up by cycling 10 times through the 4-year

404 period from 1 January 2001 to 1 January 2005. The models were then integrated in ensemble

405 mode (12 members; using the perturbations settings of Table 2) for the same 4-year period.

406 These open loop integrations also recorded the LST innovations (without applying any

407 increments) for the computation of the model and retrieval statistics that are required for the a

408 priori scaling approach. The (ensemble) assimilation integrations covered the same 4-year

409 period and were validated against the 27 months of CEOP observations from 1 October 2002

410 through 1 January 2005.

411

412 For each land model, we conducted one open loop (no assimilation) ensemble integration and

413 four different experiments in which ISCCP retrievals were assimilated assuming an observation

414 error standard deviation of $2 \mathrm{~K}$. Two of the four assimilation integrations (per model) were

415 performed with the (unscaled) ISCCP retrievals ("s0" for "no scaling"), the other two utilized

416 ISCCP retrievals that were scaled to each model’s LST climatology prior to assimilation ("s1";

417 section 4c). In each set of two assimilation integrations, one was done without bias correction

418 ("b0"), and the other used the dynamic bias algorithms ("b8"; section 4c). For each model, we

419 thus compare four assimilation integrations: "s0b0", "s0b8", "s1b0", and "s1b8".

421 All integrations were analyzed by computing RMSE values (from raw time series) and anomaly

422 correlation coefficients (R; from anomaly time series) for LST, LH, SH, and GH with respect to

423 the available in situ CEOP observations. These performance metrics were first computed 
424 separately for each station from 3-hourly time series and then averaged over the available

425 stations. Anomaly time series were computed by subtracting the monthly mean seasonal and 426 diurnal cycle (climatology) from the raw data. The climatologies and metrics were computed 427 only from data at times and locations where ISCCP retrievals were available so that only clear428 sky conditions are compared to the extent possible. Mean values for a given calendar month and 429 time-of-day are computed only if a minimum of 20 data points are available; mean monthly 430 values are computed only if mean values are available for all eight times-of-day for the month in 431 question; and performance metrics are based on at least 100 data points.

433 We analyze two performance metrics, RMSE and anomaly R, to highlight the advantages and 434 disadvantages of the various assimilation approaches. Given the typically strong seasonal and 435 diurnal cycles of LST and land surface fluxes, metrics based on raw data are dominated by errors 436 in the climatology. Metrics based on anomalies, by contrast, primarily capture day-to-day 437 variations. RMSE values measure how closely the data agree in their original units and are 438 affected by a mean bias or a mean difference in the amplitude of variations. $\mathrm{R}$ values, on the 439 other hand, are not affected by such biases and only capture the phasing between the estimates 440 and the validating observations. The choice of metric depends on the application at hand

441 (Entekhabi et al. 2010). RMSE values are most relevant if absolute errors matter most. In other 442 cases, anomaly R values may be of most relevance, for example in model-based applications 443 (such as Numerical Weather Prediction) that could correct for known biases in the mean and 444 variance. 


\section{Results}

\section{6.a. Aggregate performance}

448 The station-average RMSE and R metrics, evaluated against the CEOP in situ observations as

449 discussed in the previous section, measure the aggregate performance of the satellite, model, and

450 assimilation estimates. In this section, we highlight the performance of select assimilation

451 integrations in terms of select metrics (see appendix for a complete table of metrics and

452 algorithms). Before turning to the assimilation integrations, however, we first assess the skill of

453 the satellite retrievals and of the model integrations without assimilation (open loop). The top

454 panel of Figure 3 illustrates the RMSE values computed from the raw LST estimates, which are

455 4.9 K for CLSM (yellow bar), 5.6 K for Noah (light blue bar), and 7.6 K for ISCCP (black bar).

456 The bottom panel shows corresponding RMSE values for model estimates of LH, SH, and GH,

457 which range from 50 to $67 \mathrm{~W} \mathrm{~m}^{-2}$ and are within a factor of two of typical measurement errors

458 (around $30 \mathrm{~W} \mathrm{~m}^{-2}$ ) for surface turbulent fluxes (Finkelstein and Sims 2001, Hollinger and

459 Richardson 2005). The first important results of Figure 3 are therefore that (i) the CLSM and

460 Noah open loop integrations show similar skill when compared to CEOP in situ observations and

461 that (ii) the model estimates of LST are significantly better than ISCCP retrievals.

462

463 The situation is similar for the anomaly R metric, shown in Figure 4 for LST only. The models

464 show reasonable skill in terms of reproducing standardized anomalies, with anomaly $\mathrm{R}$ values of

465 about 0.6. Again, ISCCP retrievals are significantly less skillful than model estimates (anomaly

$466 \mathrm{R}$ value of 0.52 ). An analysis of sampling error reveals that $95 \%$ confidence intervals for all $\mathrm{R}$

467 values discussed here are less than \pm 0.01 . For RMSE values, $95 \%$ confidence intervals are less

468 than $\pm 0.1 \mathrm{~K}$ for LST and less than $\pm 1 \mathrm{~W} \mathrm{~m}^{-2}$ for surface fluxes. In the following, RMSE and 
anomaly $\mathrm{R}$ values are rounded accordingly (skill difference values rounded after computing the

470 difference).

471

472 Obviously, the superior skill of the model LST estimates relative to the skill of the ISCCP

473 retrievals limits the improvements that can be expected from assimilating the ISCCP data.

474 Nevertheless, as will be shown, modest yet statistically significant improvements can be

475 achieved through the assimilation of ISCCP LST retrievals. We expect that the use of a priori

476 scaling produces better anomaly estimates, whereas omitting a priori scaling should yield better

477 improvements in terms of absolute numbers (that is, raw data) due to likely biases in model

478 climatology. Thus, for RMSE computed from raw data (Figure 3), we focus on assimilation

479 without a priori scaling (s0b0, s0b8). The CLSM assimilation integration without dynamic bias

480 correction (s0b0; orange bars) is characterized by only minor improvements in LST (0.2 K for

481 RMSE) and virtually no changes in the land surface flux estimates (when compared to the open

482 loop skill). Recall that CLSM’s prognostic "surface temperature" represents the canopy and top

$4835 \mathrm{~cm}$ of soil and is associated with a very small heat capacity. Consequently, without dynamic

484 bias estimation and correction, increments from the assimilation of ISCCP retrievals dissipate

485 quickly and have little impact on the model state in CLSM. Increments applied to the Noah

486 model's top layer $(10 \mathrm{~cm})$ soil temperature, on the other hand, have a somewhat more noticeable

487 effect on the model state. For assimilation without a priori scaling and without dynamic bias

488 correction (s0b0), the RMSE for Noah LST estimates is improved by $0.5 \mathrm{~K}$ (medium blue bar in

489 Figure 3). As for CLSM, the Noah assimilation estimates for the latent and sensible heat fluxes

490 are comparable to the open loop estimates. However, the RMSE value for Noah s0b0 estimates

491 of $\mathrm{GH}$ increases by $11 \mathrm{~W} \mathrm{~m}^{-2}$ (more on this later).

492 
493 Next, we analyze the skill of the assimilation integrations with dynamic bias estimation and 494 correction (s0b8), also illustrated in Figure 3. For CLSM, adding dynamic bias estimation (red 495 bar) enhances the LST improvements (over the open loop) to $0.7 \mathrm{~K}$ in terms of RMSE. Using a 496 bias-corrected model forecast at every model time step (equation (5)) enhances the impact of 497 LST increments in the CLSM assimilation integrations and thereby yields enhanced 498 improvements from the assimilation of the ISCCP retrievals (relative to not using the dynamic 499 bias algorithm). For Noah, using the dynamic bias algorithm (s0b8; dark blue bar in Figure 3) 500 yields only slightly better LST than the s0b0 assimilation integration without dynamic bias 501 correction (RMSE now reduced by $0.6 \mathrm{~K}$ over the open loop). At the same time, however, the 502 deterioration of the GH estimates is exacerbated in s0b8. The RMSE value for assimilation 503 estimates of GH increases by $28 \mathrm{~W} \mathrm{~m}^{-2}$ when compared with the open loop RMSE. LH and SH 504 estimates from s0b8 are again comparable to open loop estimates.

506 For the analysis of assimilation integrations with a priori scaling (s1b0, s1b8) we focus on the 507 anomaly R metric, shown in Figure 4. Qualitatively, the results for these integrations are similar 508 to those obtained without a priori scaling. In CLSM, a priori scaling alone (s1b0) yields only 509 small improvements in LST (anomaly R increases by 0.02). Most of the impact is realized 510 through dynamic bias estimation (anomaly R for LST increases by 0.05 over the open loop). For 511 Noah, on the other hand, the anomaly R for LST already increases by 0.04 (over the open loop) 512 when only a priori scaling is applied. The estimates get only slightly better when dynamic bias 513 correction is added (increase of 0.05 in anomaly R for LST). There is also a deterioration in the

514 Noah GH estimates (relative to the open loop) when a priori scaling is used (with or without bias 515 correction), but generally the loss of skill in GH is mitigated through a priori scaling (not shown, 516 see appendix). Noah assimilation estimates of LH and SH have marginally better anomaly R 
517 values than open loop estimates (not shown), but these improvements are so small that we do not

518 consider them to be relevant.

520 In summary, using dynamic bias estimation for CLSM (s0b8, s1b8) provides the best

521 assimilation estimates and enables modest LST improvements (over the open loop) of up to 0.7

$522 \mathrm{~K}$ in terms of RMSE and up to 0.05 in terms of anomaly R. Flux estimates from these CLSM

523 assimilation integrations are essentially identical to open loop estimates - assimilation of LST

524 does not lead to improved flux estimation. For Noah, assimilation without a priori scaling and

525 without dynamic bias estimation (s0b0) already yields most of the benefit of assimilating the

526 satellite retrievals. Using a priori scaling and/or dynamic bias estimation yields only small

527 additional improvements. For Noah, LST improvements (over the open loop) are similar to

528 those for CLSM: up to $0.6 \mathrm{~K}$ for RMSE and up to 0.05 in terms of anomaly R. Noah

529 assimilation estimates of SH and LH are similar to the open loop estimates, but the assimilation

530 estimates of GH are considerably worse than the open loop estimates (up to $28 \mathrm{~W} \mathrm{~m}^{-2}$ increase in

531 RMSE), with lesser degradation seen when a priori scaling is used. Without a priori scaling, the

532 worsening of the GH estimates in Noah may well outweigh the benefits of the LST

533 improvements.

535 As shown in Figure 1 and Table 1, most CEOP stations either have LST and GH measurements 536 or have LH and SH measurements. Only four stations measure LST and all three fluxes. The

537 results in this section must be interpreted with this caveat in mind. Conceivably, if a large

538 number of stations were able to provide LST, LH, and SH measurements together, and if our

539 analyses were limited to that set of stations, we might indeed be able to show that improved LST

540 estimates from assimilation correspond to improved estimates of the turbulent fluxes. Given the 
541 limitations of the available in situ measurements, we cannot know for sure. Note, however, that

54215 out of the 19 stations that have LST measurements also have GH measurements, suggesting

543 that for Noah the LST improvements from assimilation are connected to the worsening of GH

544 estimates.

545

546 As discussed in section 5, the RMSE and anomaly R values shown here are based on 3-h average

547 data, including nighttime and wintertime when fluxes are small and noise may overwhelm the

548 signal. In a separate analysis (not shown) we also computed the performance metrics from daily

549 average data. While RMSE values are generally lower when based on daily averages (as can be

550 expected from increased averaging) and $\mathrm{R}$ values are also somewhat different in overall

551 magnitude, the relative performance is similar regardless of whether metrics are computed from

552 daily or 3-h average data, and the main conclusions of this section thus remain unchanged.

553 In a second separate analysis (not shown), we assessed the performance based strictly on

554 summertime data and again find that our conclusions remain the same.

\section{6.b. Seasonal and diurnal cycles}

557 Estimates of the mean seasonal and diurnal cycles provide additional insights into the modeling

558 and assimilation of LST. Figure 5 (left panels) shows the mean seasonal cycle of LST at two

559 locations, Bondville in the US Midwest and BJ-SAWS3 in Tibet. At both locations, the seasonal

560 cycle estimates of the CLSM and Noah open loop integrations agree fairly closely with each

561 other (to within $2 \mathrm{~K}$ ), primarily because both models are driven with the same surface

562 meteorological forcing data. At Bondville, the open loop estimates of the seasonal cycle also

563 agree closely with the in situ CEOP observations. At the Tibetan station, however, the open loop

564 estimates are biased low by about $5 \mathrm{~K}$ (relative to the in situ observations). In contrast, ISCCP 
565 estimates of the seasonal cycle are biased high by about $3 \mathrm{~K}$ at BJ-SAWS3 and differ by up to 5

$566 \mathrm{~K}$ in the first half of the year at Bondville.

568 By construction, the seasonal and diurnal cycle estimates of assimilation integrations with a 569 priori scaling closely match those of the open loop integration (not shown). Figure 5 also shows

570 the seasonal climatology of assimilation integrations without a priori scaling and with dynamic

571 bias estimation and correction (s0b8). As expected, the s0b8 assimilation integrations draw more

572 closely to the ISCCP retrievals (when compared to the open loop). At BJ-SAWS3, this

573 fortuitously brings the assimilation estimates of the seasonal cycle into better agreement with the 574 in situ observations than either the ISCCP or the open loop estimates.

576 Figure 5 (right panels) also illustrates the mean August diurnal cycle estimates at Bondville and 577 BJ-SAWS3. At Bondville, the Noah open loop estimates have a slightly higher diurnal 578 amplitude than the CLSM estimates (because LST for Noah exceeds that of CLSM by up to $2 \mathrm{~K}$ 579 during the day and by less than $1 \mathrm{~K}$ during the night). At BJ-SAWS3, the open loop integrations 580 agree closely with each other. Similar to the seasonal cycle estimates, the open loop estimates at 581 Bondville are in reasonable agreement with the in situ observations but are biased low (by about $5825 \mathrm{~K})$ at BJ-SAWS3. ISCCP retrievals, on the other hand, exhibit a weaker diurnal amplitude at 583 Bondville than model or in situ observations. At BJ-SAWS3, ISCCP retrievals are biased high 584 (compared to the in situ observations) in the morning and mid-day but biased low in the evening 585 and at nighttime.

587 Again, the LST diurnal cycle estimates of the CLSM s0b8 assimilation integrations draw towards 588 the ISCCP retrievals by construction (Figure 5, right panels). This brings them closer to the in 
situ observations at BJ-SAWS3 but makes CLSM nighttime estimates at Bondville worse when

590 compared to the open loop. By contrast, LST from the Noah s0b8 assimilation integration is

591 similar to the open loop integration during daytime. Only during the evening hours (at Bondville

592 and BJ-SAWS3) are the Noah s0b8 LST estimates noticeably closer to the ISCCP retrievals.

593 The delayed impact of the LST assimilation is probably a result of the phase lag between the

594 diagnostic LST (observations space) and the top layer soil temperature (state space) in Noah.

595

596 6.c. Filter diagnostics

597 Internal filter diagnostics offer further clues about the performance of the assimilation

598 algorithms. For a filter that operates according to its underlying assumptions (that various

599 linearizations hold, that model and observation errors are unbiased, uncorrelated and normally

600 distributed), the time average of the (ensemble mean) innovations sequence $\left(\mathrm{y}_{\mathrm{t}}-\mathrm{H}_{\mathrm{t}} \mathrm{x}_{\mathrm{t}}{ }^{-}\right)$equals

601 zero. Moreover, the standard deviation of the "normalized" innovations $\left(\mathrm{y}_{t}-\mathrm{H}_{\mathrm{t}} \mathrm{x}_{\mathrm{t}}^{-}\right) \cdot\left(\mathrm{H}_{\mathrm{t}} \mathrm{P}_{\mathrm{x}, \mathrm{t}} \mathrm{H}_{\mathrm{t}}^{\mathrm{T}}\right.$

$\left.602+\mathrm{R}_{\mathrm{t}}\right)^{-0.5}$ equals one (Reichle et al. 2002a). The latter diagnostic compares the actual spread in the

603 innovations to what the filter expects. A simple interpretation is that the assumed error bars of a

604 model forecast and its corresponding observation must have an appropriate overlap.

605

606 Figure 6 displays the distribution of these two internal filter diagnostics across the CEOP stations

607 listed in Table 1. The top panel indicates that without a priori scaling of the ISCCP observations 608 and without dynamic bias estimation (s0b0), biases of several Kelvin typically persist in the 609 model forecast and are reflected in the mean of the innovations. (The innovations statistics of

610 the open loop integrations are essentially the same as those of the s0b0 integrations and are not

611 shown in the figure.) A very modest reduction of the bias can be achieved with the "b8"

612 dynamic bias estimation algorithm. If in addition to dynamic bias estimation the observations 
613 are also scaled prior to data assimilation (s1b8), the innovations mean at all stations is, by

614 construction, much closer to zero. These results hold for assimilation into both land models,

615 CLSM and Noah.

616

617 The standard deviation of the normalized innovations, shown in the bottom panel of Figure 6,

618 exceeds the target value of one at almost all stations and for almost all algorithms. This indicates

619 that the model and/or the observation error standard deviations were underestimated. Like for

620 the innovations mean, a priori scaling brings the standard deviation of the normalized

621 innovations much closer to its expected value of one. This implies that a large part of the

622 mismatch between the actual spread in the innovations and the expected spread is simply due to

623 bias. Finally, the fact that the innovations diagnostics are comparable for the CLSM and Noah

624 assimilation integrations indicates that the assimilation performance (relative to its unknown

625 optimum) is comparable for the two models, which lends further support to the broad

626 conclusions reached in this paper. In summary, a priori scaling in combination with dynamic

627 bias estimation exhibits the best performance in terms of the innovations diagnostics,

628 independent of the land model used.

629

630 6.d. Impact of bias in data assimilation

631 Estimates from a properly designed assimilation system should be no worse than open loop

632 estimates. The example in Figure 7 further illustrates the potentially serious detrimental impact

633 of not addressing bias properly in data assimilation. The figure shows LST and land surface flux

634 time series from select Noah integrations for a few days in August of 2003 at the MGS station in

635 Mongolia. At this location, LST and GH estimates from the open loop integrations agree fairly

636 well with CEOP in situ observations. The daytime peak LST estimates from ISCCP, however, 
637 are warmer by as much as $30 \mathrm{~K}$. This extreme bias may be due to one or more of the reasons

638 discussed in section 2.

640 At any rate, when the unscaled ISCCP retrievals are assimilated without a priori scaling (s0b0,

641 s0b8), LST assimilation estimates are drawn toward the extreme temperatures in the ISCCP

642 retrievals (Figure 7). However, since Noah is not designed to accommodate such extreme

643 temperatures, and because the surface meteorological forcing remains unchanged in the system,

644 the Noah assimilation integrations without a priori scaling respond with unrealistic and excessive

645 estimates of sensible and ground heat flux, most notably on 13 August 2003. Because the impact

646 on LST of assimilating unscaled ISCCP retrievals without bias correction (s0b0) is more limited,

647 the corresponding flux estimates are less pathological than in the s0b8 case with dynamic bias

648 correction. For reference, Figure 7 also shows an assimilation integration with a priori scaling

649 and dynamic bias correction (s1b8), which does not produce such unrealistic flux estimates.

651 The situation is similar for LST from CLSM assimilation integrations for the same location and

652 time period (not shown), but for CLSM we obtain unrealistic estimates of the latent heat flux for

653 select assimilation integrations without a priori scaling. To summarize, Figure 7 illustrates the

654 pitfalls of assimilating LST retrievals that are severely biased against model LST. While the

655 assimilation can be designed to produce LST estimates that are closer to the satellite retrievals,

656 there may be unintended and undesirable side effects in terms of the land surface fluxes and the

657 surface energy balance.

658 


\section{Summary and conclusions}

660 An ensemble-based data assimilation method, the EnKF, was used with and without a priori

661 scaling of observations and/or dynamic bias estimation methods to assimilate satellite retrievals

662 of LST into two different land surface models at 48 CEOP sites scattered around the globe. The

663 two land models, CLSM and Noah, follow distinct modeling approaches for land surface

664 temperature. CLSM has model prognostic "surface temperature" variables, whereas Noah

665 diagnoses the surface temperature from the surface energy balance. The LST, sensible, latent,

666 and ground heat flux estimates from the data assimilation integrations were validated against 27

667 months of CEOP in situ observations.

669 The main conclusions from the experiments are as follows.

670 (1) There are strong biases between LST estimates from in situ observations, land modeling, and

671 satellite retrievals that vary with season and time-of-day. Biases of a few Kelvin are typical,

672 with larger values exceeding $10 \mathrm{~K}$.

673 (2) The skill of LST estimates from the CLSM and Noah land model integrations is superior to

674 that of the ISCCP satellite retrievals.

675 (3) Assimilation of ISCCP LST retrievals into the land surface models can improve LST

676 estimates by up to $0.7 \mathrm{~K}$ for RMSE and by up to 0.05 for anomaly R, while not making surface

677 turbulent fluxes worse.

678 (4) Gross errors in surface flux estimates can result if biases are not taken into account properly,

679 with a combination of a priori scaling and dynamic bias estimation methods yielding the best

680 overall results. 
681 (5) Assimilation diagnostics for integrations without a priori scaling strongly reflect the

682 underlying biases, indicating that without a priori scaling the assimilation system is far from

683 operating in accordance with its underlying assumptions.

684 (6) Provided the assimilation system is properly configured for each land model, the benefits 685 from the assimilation of LST retrievals are comparable for both land models.

687 There are many reasons why the improvements from the assimilation of satellite LST, while

688 statistically significant, turn out to be modest. First and foremost, the skill of the satellite data is

689 modest and much lower than that of the model to begin with. The information gained by

690 assimilating the satellite data into the model is therefore naturally limited. In the present study,

691 the parameters of the assimilation system, including the perturbations (or model error)

692 parameters and the parameters of the bias algorithm $(\alpha, \gamma)$ were not optimized. Additional

693 calibration may further improve the results and may also reveal differences in what can be

694 achieved with a given land model structure. Finally, even if the assimilation estimates were

695 perfect, the performance metrics would not show it because of errors in the in situ data and

696 because of the mismatch of the spatial and temporal characteristics of the satellite, model, and in 697 situ data sets.

698

699 By design, the present study was limited to LST (state) estimation in an uncoupled land

700 modeling system. Ideally, the land model parameters would be calibrated to minimize LST

701 biases prior to data assimilation, or perhaps even dynamically within the data assimilation

702 system. Such a calibration could rely on sophisticated parameter estimation methods (Vrugt et

703 al. 2003). Perhaps more importantly, though, is that the surface meteorological forcings in the 
704 present experiments were fixed. In other words, LST increments did not feed back onto the 705 atmospheric state. Future experiments will explore LST assimilation into a coupled land-

706 atmosphere model with the methods proposed here. The relative performance of the algorithms 707 may very well change in the coupled environment.

708

709 Another path for future research is to investigate further the role of specific aspects of LST

710 modeling. In the present paper, Noah was integrated in its default configuration, including a 10

711 cm thick surface layer, which implied a small phase shift between the Noah diagnostic LST

712 (used in the computations of the innovations) and the Noah top soil temperature (to which the

713 increments were applied). Use of a thinner soil layer may alleviate the problems related to the

714 phase shift in Noah between LST (observation space) and the top layer soil temperature (state 715 space).

716

717 Even if the assimilation manages to improve LST only modestly and fluxes not at all, the impact

718 may be significant because minor improvements in LST may already increase the number of

719 atmospheric retrievals that can be assimilated in coupled systems, thereby possibly providing

720 substantial indirect benefits. Obviously, the present study only scratches the surface of a very

721 complex problem that has been a challenge for many years. Nevertheless, given the relative

722 abundance of LST observations from satellites and the importance of accurate LST estimates, in

723 particular in the context of atmospheric data assimilation, the results of the present study offer an

724 encouraging step forward in land data assimilation.

725

726 


\section{Appendix}

728 In addition to the dynamic bias algorithm "b8" discussed in section 4c we also tested additional

729 variants of the algorithm used by Bosilovich et al. (2007). Specifically, we tested the simplest

730 possible variant that estimates a single, "mean" bias estimation parameter per state and per

731 location, here referred to as "b1". Bosilovich et al. (2007) also introduced a bias

732 parameterization with sine and cosine functions that accounts for variations in the diurnal cycle

733 of the bias. Here we implemented two variants: a "diurnal" bias parameterization (constant term

734 plus sine and cosine waves with a period of one day) and a "semi-diurnal" bias parameterization

735 ("diurnal" terms plus sine and cosine waves with a period of one half day). The "diurnal" and

736 "semi-diurnal" algorithms estimate three and five bias parameters, respectively, per state and

737 location, and are referred to as "b3" and "b5".

739 For the "b8" integrations discussed in the main text we always applied both the state increments

740 (equation (2)) and the bias increments (equation (6)). More generally, though, any assimilation

741 integration that uses dynamic bias estimation can also be done without applying the state

742 increments (as, in fact, implemented by Bosilovich et al. (2007)). We also tested these variants.

743 Per model, we therefore tested a total of 18 different assimilation integrations, listed in Table 3.

745 A close examination of Table 3 reveals that generally, the assimilation integrations show more

746 skill when more bias parameters are used. Reductions in RMSE values for LST are greater by up

747 to $0.4 \mathrm{~K}$ for CLSM and by up to $0.2 \mathrm{~K}$ for Noah when comparing "b8" and "b1"integrations.

748 Corresponding differences in anomaly R values for LST are up to 0.03, respectively, for both

749 models. As can be expected, these differences across bias estimation algorithms of varying 
750 complexity tend to be greater without a priori scaling. Also in line with expectations, taking

751 into account the diurnal cycle of the bias (as in "b3", "b5", and "b8", as opposed to "b1") has the

752 biggest impact.

753

754 Finally, applying the state increments in addition to the bias increments contributes only a small

755 amount of skill, typically less than $0.1 \mathrm{~K}$ in terms of RMSE reduction (or 0.01 in terms of $\mathrm{R}$

756 increase) for LST estimates. In the case of Noah, applying the state increments contributes

757 commensurately to the worsening of the GH estimates.

758

759 To summarize, as long as the dynamic bias algorithm takes the diurnal cycle into account, the

760 differences that result from the exact number of bias parameters used or that result from not

761 applying the state increments are much smaller than the assimilation improvements over the

762 open loop. In other words, the lessons learned in the main text about assimilation of LST

763 retrievals in general and about using a priori scaling and/or dynamic bias correction are

764 insensitive to the details of the dynamic bias estimation algorithm, provided the algorithm

765 considers the diurnal cycle of the bias.

766 


\section{Acknowledgments}

768 Thanks to Michael Bosilovich, John Eylander, and Christa Peters-Lidard for helpful comments.

769 Partial support for this study was provided through NASA (NNX08AH36G) and the Air Force

770 Weather Agency (F2BBBJ7080G001). We are grateful for access to the many data sets that

771 supported this work, in particular the CEOP and ISCCP projects. Surface meteorological data

772 were provided by H. Kato, J. Meng, and M. Rodell of the GLDAS project, with data

773 contributions from the NOAA Earth System Research Laboratory. Computing was supported by

774 the NASA High End Computing Program.

775 


\section{References}

777 Aires, F., C. Prigent, and W. B. Rossow, 2004: Temporal interpolation of global surface skin

778 temperature diurnal cycle over land under clear and cloudy conditions, Journal of

779 Geophysical Research, 109, D06214, doi:10.1029/2003JD003527.

780 Andreadis, K. and D. Lettenmaier, 2005: Assimilating remotely sensed snow observations into a

781 macroscale hydrology model, Advances in Water Resources, 29, 872-886.

782 Balsamo, G., J.-F. Mahfouf, and S. Belair, 2007: A land data assimilation system for soil

783 moisture and temperature: An information content study, Journal of Hydrometeorology, 8,

784 1225-1242, doi:10.1175/2007JHM819.1.

785 Bloom, S., A. da Silva, D. Dee, M. Bosilovich, J.-D. Chern, S. Pawson, S. Schubert, M.

786 Sienkiewicz, I. Stajner, W.-W. Tan, and M.-L. Wu, 2005: Documentation and Validation of

787 the Goddard Earth Observing System (GEOS) Data Assimilation System - Version 4,

788 Technical Report Series on Global Modeling and Data Assimilation, Global Modeling and

789 Assimilation Office, NASA Goddard Space Flight Center, 187 pp., Document number

$790 \quad$ 104606, 26.

791 Boni, G., D. Entekhabi, and F. Castelli, 2001: Land data assimilation with satellite measurements

792 for the estimation of surface energy balance components and surface control on evaporation,

$793 \quad$ Water Resources Research, 37, 1713-1722.

794 Bosilovich, M., J. Radakovich, A. da Silva, R. Todling, and F. Verter, 2007: Skin temperature

795 analysis and bias correction in a coupled land-atmosphere data assimilation system, J. Meteo.

796 Soc. Japan, 85A, 205-228. 
797 Caparrini, F., F. Castelli, and D. Entekhabi, 2004: Variational estimation of soil and vegetation 798 turbulent transfer and heat flux parameters from sequences of multisensor imagery, Water 799 Resources Research, 40, W12515, doi:10.1029/2004WR003358.

800 Castelli, F., D. Entekhabi, and E. Caporali, 1999) Estimation of surface heat flux and an index of 801 soil moisture using adjoint-state surface energy balance, Water Resources Research, 35, $802 \quad 3115-3125$.

803 Crow, W. T., and R. H. Reichle, 2008: Comparison of adaptive filtering techniques for land 804 surface data assimilation, Water Resources Research, 44, W08423, 805 doi:10.1029/2008WR006883.

806 Crow, W. T., and E. F. Wood, 2003: The assimilation of remotely sensed soil brightness 807 temperature imagery into a land surface model using ensemble Kalman filtering: A case 808 study based on ESTAR measurements during SGP97, Adv. Water Resour., 26, 137-149.

809 De Lannoy, G. J. M., R. H. Reichle, P. R. Houser, V. R. N. Pauwels, and N. E. C. Verhoest, 810 2007: Correcting for Forecast Bias in Soil Moisture Assimilation with the Ensemble Kalman

811 Filter, Water Resources Research, 43, W09410, doi:10.1029/2006WR005449.

812 Dee, D. P., 2005: Bias and data assimilation, Q. J. R. Meterol. Soc., 131, 3323-3343, 813 doi:10.1256/qj.05.137.

814 Drusch, M., 2007: Initializing numerical weather prediction models with satellite derived surface 815 soil moisture: Data assimilation experiments with ECMWF's Integrated Forecast System and 816 the TMI soil moisture dataset, J. Geophys. Res., 112 (D3), Art. No. D03102, 817 doi:10.1029/2006JD007478. 
818 Dunne, S., and D. Entekhabi, 2006: Land surface state and flux estimation using the ensemble

819 Kalman smoother during the Southern Great Plains 1997 field experiment, Water Resour.

820 Res., 42, W01407, doi:10.1029/2005WR004334.

821 Ek, M., K. Mitchell, L. Yin, P. Rogers, P. Grunmann, V. Koren, G. Gayno, and J. D. Tarpley,

822 2003: Implementation of Noah land-surface model advances in the NCEP operational

823 mesoscale Eta model, J Geophys Res., 108, doi:10.1029/2002JD003296.

824 Entekhabi, D., R. H. Reichle, R. D. Koster, and W. T. Crow, 2010: Performance Metrics for Soil

825 Moisture Retrievals and Application Requirements, J. Hydrometeor., submittted.

826 Finkelstein, P. L., and P. F. Sims, 2001: Sampling error in eddy correlation flux measurements,

827 J. Geophys. Res., 106(D4), 3503-3509.

828 Garand, L., 2003: Toward an Integrated Land-Ocean Surface Skin Temperature Analysis from

829 the Variational Assimilation of Infrared Radiances, J. Appl. Meteorol., 42, 570-583.

830 Hollinger, D. Y., and A. D. Richardson, 2005: Uncertainty in eddy covariance measurements and

831 its application to physiological models, Tree Physiology, 25, 873-885.

832 Jin, M., 2004: Analysis of land skin temperature using AVHRR observations, Bulletin of the

833 American Meteorological Society, 85, 587-+, doi:10.1175/BAMS-85-4-587.

834 Jin, M. L., R. E. Dickinson, and A. M. Vogelmann, 1997: A comparison of CCM2-BATS skin

835 temperature and surface-air temperature with satellite and surface observations, Journal of

$836 \quad$ Climate, 10, 1505-1524.

837 Keppenne C. L., 2000: Data assimilation into a primitive-equation model with a parallel

838 ensemble Kalman filter, Mon. Wea. Rev., 128, 1971-1981 
839 Koster, R. D., M. J. Suarez, A. Ducharne, M. Stieglitz, and P. Kumar, 2000: A catchment-based

840 approach to modeling land surface processes in a general circulation model, 1: Model

841 structure. Journal of Geophysical Research, 105, 24809-24822.

842 Kumar, P., and A. L. Kaleita, 2003: Assimilation of near-surface temperature using extended 843 Kalman filter, Advances in Water Resources, 26, 79-93.

844 Kumar, S. V., R. H. Reichle, C. D. Peters-Lidard, R. D. Koster, X. Zhan, W. T. Crow, J. B.

845 Eylander, and P. R. Houser, 2008: A Land Surface Data Assimilation Framework using the

846 Land Information System: Description and Applications, Advances in Water Resources, 31, 847 1419-1432, doi:10.1016/j.advwatres.2008.01.013.

848 Lakshmi, V., 2000: A simple surface temperature assimilation scheme for use in land surface 849 models, Water Resources Research, 36, 3687-3700.

850 Mahfouf, J.-F., K. Bergaoui, C. Draper, F. Bouyssel, F. Taillefer, and L. Taseva, 2009: A

851 comparison of two off-line soil analysis schemes for assimilation of screen level

852 observations, J. Geophys. Res., 114, D08105, doi:10.1029/2008JD011077.

853 Margulis, S. A., D. McLaughlin, D. Entekhabi, and S. Dunne, 2002: Land data assimilation and 854 estimation of soil moisture using measurements from the Southern Great Plains 1997 field 855 experiment, Water Resour. Res., 38, 1299, doi:10.1029/2001WR001114.

856 McNider, R. T., A. J. Song, D. M. Casey, P. J. Wetzel, W. L. Crosson, and R. M. Rabin, 1994: 857 Toward a dynamic-thermodynamic assimilation of satellite surface-temperature in numerical 858 atmospheric models, Monthly Weather Review, 122, 2784-2787.

859 Meng, C. L., Z.-L. Li, X. Zhan, J. C. Shi, and C. Y. Liu, 2009: Land surface temperature data 860 assimilation and its impact on evapotranspiration estimates from the Common Land Model, 861 Water Resour. Res., 45, W02421, doi:10.1029/2008WR006971. 
Minnis, P., and M. M. Khaiyer, 2000: Anisotropy of Land Surface Skin Temperature Derived

863 from Satellite Data., J. Appl. Meteor., 39, 1117-1129.

864 Pan, M., and E. F. Wood, 2006: Data Assimilation for Estimating the Terrestrial Water Budget

865 Using a Constrained Ensemble Kalman Filter, J. Hydrometeorol., 7, 534-547.

866 Pinheiro, A. C. T., J. L. Privette, R. Mahoney, and C. J. Tucker, 2004: Directional effects in a

867 daily AVHRR land surface temperature dataset over Africa, IEEE Transactions on

868 Geosciences Remote Sensing, 42, 1941-1954, doi:10.1109/TGRS.2004.831886.

869 Reichle, R. H., and R. D. Koster, 2003: Assessing the impact of horizontal error correlations in

870 background fields on soil moisture estimation, J. Hydrometeorol., 4 (6), 1229-1242.

871 Reichle, R. H., and R. D. Koster, 2004: Bias reduction in short records of satellite soil moisture,

872 Geophys. Res. Lett., 31, doi:10.1029/2004GL020938.

873 Reichle, R. H., D. McLaughlin, and D. Entekhabi, 2002a: Hydrologic data assimilation with the

874 Ensemble Kalman filter, Mon. Weather Rev. 130(1), 103-114.

875 Reichle, R. H., J. P. Walker, R. D. Koster, and P. R. Houser, 2002b: Extended versus Ensemble

876 Kalman filtering for land data assimilation, J. Hydrometeorol., 3(6), 728-740.

877 Reichle, R. H., R. D. Koster, P. Liu, S. P. P. Mahanama, E. G. Njoku, and M. Owe, 2007:

878 Comparison and assimilation of global soil moisture retrievals from the Advanced

879 Microwave Scanning Radiometer for the Earth Observing System (AMSR-E) and the

880 Scanning Multichannel Microwave Radiometer (SMMR), J. Geophys. Res., 112, D09108,

881 doi:10.1029/2006JD008033.

882 Reichle, R. H., W. T. Crow, and C. L. Keppenne, 2008: An adaptive ensemble Kalman filter for

883 soil moisture data assimilation, Water Resources Research, 44, W03423,

884 doi:10.1029/2007WR006357. 
Reichle, R. H., M. G. Bosilovich, W. T. Crow, R. D. Koster, S. V. Kumar, S. P. P. Mahanama, and B. F. Zaitchik, 2009: Recent Advances in Land Data Assimilation at the NASA Global Modeling and Assimilation Office, in Data Assimilation for Atmospheric, Oceanic and Hydrologic Applications, edited by Seon K. Park and Liang Xu, 407-428, Springer Verlag, New York, doi:10.1007/978-3-540-71056-1.

Rodell, M., and P. R. Houser, 2004: Updating a land surface model with MODIS-derived snow cover, Journal of Hydrometeorology, 5, 1064-1075.

Rodell, M., P. R. Houser, U. Jambor, J. Gottschalck, K. Mitchell, C.-J. Meng, K. Arsenault, B. Cosgrove, J. Radakovich, M. Bosilovich, J. K. Entin, J. P. Walker, and D. L. Toll, 2003: The Global Land Data Assimilation System, Bull. Amer. Meteorol. Soc., 85, 381-394, doi:10.1175/BAMS-85-3-381.

Rossow, W. B., and R. A. Schiffer, 1991: ISCCP cloud data products, Bulletin of the American Meteorological Society, 72, 2-20.

Rossow, W. B., and R. A. Schiffer, 1999: Advances in understanding clouds from ISCCP, Bulletin of the American Meteorological Society, 80, 2261-2287.

Seuffert, G., H. Wilker, P. Viterbo, J.-F. Mahfouf, M. Drusch, and J.-C. Calvet, 2003: Soil moisture analysis combining screen-level parameters and microwave brightness temperature: A test with field data, Geophys. Res. Lett., 30, 1498, doi:10.1029/2063GL017128.

Sini, F., G. Boni, F. Caparrini, and D. Entekhabi, 2008: Estimation of large-scale evaporation fields based on assimilation of remotely sensed land temperature, Water Resources Research, 44, W06410, doi:10.1029/2006WR005574.

Slater, A., and M. Clark, 2006: Snow data assimilation via an ensemble Kalman filter, J. Hydrometeorol., 7, 478-493. 
908 Trigo, I. F., and P. Viterbo, 2003: Clear-sky window channel radiances: A comparison between 909 observations and the ECMWF model, Journal of Applied Meteorology, 42, 1463-1479.

910 Walker, J. P., G. R. Willgoose, and J. D. Kalma, 2001: One-dimensional soil moisture profile

911 retrieval by assimilation of near-surface observations: a comparison of retrieval algorithms, 912 Adv. Water Resour. 24, 631-650.

913 Van den Hurk, B. J. J. M., L. Jia, C. Jacobs, M. Menenti, and Z. L. Li, 2002: Assimilation of 914 land surface temperature data from ATSR in an NWP environment - a case study, 915 International Journal of Remote Sensing, 23, 5193-5209.

916 Vrugt, J. A., H. V. Gupta, L. A. Bastidas, W. Bouten, S. Sorooshian, 2003: Effective and 917 efficient algorithm for multiobjective optimization of hydrologic models, Water Resources 918 Research, 39, W1214, doi: 10.1029/2002WR001746.

919 Wan, Z. and Z.-L. Li,, 1997: A physics-based algorithm for retrieving land-surface emissivity 920 and temperature from EOS/MODIS data, IEEE Trans. Geosci. Remote Sens., 35, 980-996.

921 Zaitchik, B.F., and M. Rodell, 2009: Forward-Looking Assimilation of MODIS-Derived Snow-

922 Covered Area into a Land Surface Model, J. Hydrometeor., 10, 130-148, 923 doi:10.1175/2008JHM1042.1.

924 Zhou, Y., D. McLaughlin, and D. Entekhabi, 2006: Assessing the Performance of the Ensemble 925 Kalman Filter for Land Surface Data Assimilation, Mon. Weather Rev. 134, 2128-2142. 


\section{Table captions}

928

929 Table 1. CEOP stations with sufficient in situ LST, LH, SH, or GH observations for validation 930 (CSE=Continental-Scale Experiment).

931

932 Table 2. Parameters for perturbations to meteorological forcing inputs and model prognostic 933 variables.

934

935 Table 3. Skill of model and assimilation integrations versus CEOP in situ observations.

936 Integrations shown in bold face are those discussed in the main text. Anomaly R for LST from 937 ISCCP is 0.52 , RMSE is $7.6 \mathrm{~K}$.

938

939 


\section{Figure captions}

942 Fig. 1. Location of CEOP stations. Stations suitable for validation are indicated with circles

943 (SH, LH, 30 stations), plus signs (GH, 20 stations), and crosses (LST, 19 stations).

944

945 Fig. 2. LST is described in (left) CLSM with a prognostic variable ("TSURF") and in (right)

946 Noah with a diagnostic variable ("TSKIN"). LST increments are applied to "TSURF" in CLSM

947 and to "TSOIL1" in Noah (section 4.b.).

948

949 Fig. 3. RMSE versus CEOP in situ observations for (top) LST and (bottom) flux estimates from

950 ISCCP retrievals (LST only), model integrations, and select assimilation integrations without a

951 priori scaling.

952

953 Fig. 4. R versus CEOP in situ observations for LST anomalies from ISCCP retrievals, model

954 integrations, and select assimilation integrations with a priori scaling.

955

956 Fig. 5. LST (left) annual seasonal and (right) August diurnal cycle at (top) Bondville and

957 (bottom) BJ-SAWS3 for CEOP, ISCCP, model, and assimilation data.

958

959 Fig. 6. (Top) Mean of innovations [K] and (bottom) standard deviation of normalized

960 innovations [dimensionless] for (C) Catchment and (N) Noah assimilation integrations. The box

961 plots indicate the average, standard deviation, minimum and maximum of the respective

962 innovations diagnostic across the stations listed in Table 1. 
964 Fig. 7. (Top) LST, (upper middle) LH, (lower middle) SH, and (bottom) GH for Noah 965 integrations, ISCCP retrievals, and CEOP observations at the MGS station. 


\begin{tabular}{|c|c|c|c|c|c|c|c|}
\hline \multicolumn{3}{|c|}{ CEOP Identifier } & \multicolumn{2}{|c|}{ Coordinates } & \multicolumn{3}{|c|}{ Data Availability } \\
\hline CSE & Reference Site & Station & Lat & Lon & LST & $\mathbf{L H}+\mathbf{S H}$ & GH \\
\hline BALTEX & Cabauw & Cabauw & 51.97 & 4.93 & yes & yes & yes \\
\hline BALTEX & Lindenberg & Falkenberg & 52.17 & 14.12 & yes & yes & yes \\
\hline BALTEX & Lindenberg & Forest & 52.18 & 13.95 & yes & yes & yes \\
\hline CAMP & ChaoPhrayaRiver & Lampang & 18.40 & 99.47 & no & no & yes \\
\hline CAMP & Himalayas & Pyramid & 27.96 & 86.81 & no & no & yes \\
\hline CAMP & Mongolia & BTS & 46.78 & 107.14 & yes & no & yes \\
\hline CAMP & Mongolia & DGS & 46.13 & 106.37 & yes & no & yes \\
\hline CAMP & Mongolia & DRS & 46.21 & 106.71 & yes & no & yes \\
\hline CAMP & Mongolia & MGS & 45.74 & 106.26 & yes & no & yes \\
\hline CAMP & NorthEastThai & Nakhonrachasima & 14.47 & 102.38 & yes & no & yes \\
\hline CAMP & Tibet & Amdo-Tower & 32.24 & 91.62 & no & no & yes \\
\hline CAMP & Tibet & ANNI-AWS & 31.25 & 92.17 & yes & no & yes \\
\hline CAMP & Tibet & BJ-SAWS1 & 31.37 & 91.90 & yes & no & no \\
\hline CAMP & Tibet & BJ-SAWS2 & 31.37 & 91.90 & yes & no & no \\
\hline CAMP & Tibet & BJ-SAWS3 & 31.37 & 91.90 & yes & no & no \\
\hline CAMP & Tibet & BJ-Tower & 31.37 & 91.90 & yes & no & yes \\
\hline CAMP & Tibet & D105-AWS & 33.06 & 91.94 & yes & no & yes \\
\hline CAMP & Tibet & D66-AWS & 35.52 & 93.78 & yes & no & no \\
\hline CAMP & Tibet & Gaize & 32.30 & 84.05 & yes & no & yes \\
\hline CAMP & Tibet & MS3478-AWS & 31.93 & 91.71 & yes & no & yes \\
\hline CAMP & Tibet & MS3608-AWS & 31.23 & 91.78 & yes & no & no \\
\hline CAMP & Tongyu & Cropland & 44.42 & 122.87 & no & yes & yes \\
\hline CAMP & Tongyu & Grassland & 44.42 & 122.87 & no & yes & yes \\
\hline GAPP & Bondville & Bondville & 40.01 & -88.29 & yes & yes & yes \\
\hline GAPP & SGP & E 1 Larned & 38.20 & -99.32 & no & yes & no \\
\hline GAPP & SGP & E 2 Hillsboro & 38.31 & -97.30 & no & yes & no \\
\hline GAPP & SGP & E 3 Le_Roy & 38.20 & -95.60 & no & yes & no \\
\hline GAPP & SGP & E 4 Plevna & 37.95 & -98.33 & no & yes & no \\
\hline GAPP & SGP & E 5 Halstead & 38.11 & -97.51 & no & yes & no \\
\hline GAPP & SGP & E 6 Towanda & 37.84 & -97.02 & no & yes & no \\
\hline GAPP & SGP & E 7 Elk_Falls & 37.38 & -96.18 & no & yes & no \\
\hline GAPP & SGP & E 8 Coldwater & 37.33 & -99.31 & no & yes & no \\
\hline GAPP & SGP & E 9 Ashton & 37.13 & -97.27 & no & yes & no \\
\hline GAPP & SGP & E 10 Tyro & 37.07 & -95.79 & no & yes & no \\
\hline GAPP & SGP & E 12 Pawhuska & 36.84 & -96.43 & no & yes & no \\
\hline GAPP & SGP & E 13 Lamont & 36.60 & -97.48 & no & yes & no \\
\hline GAPP & SGP & E 14 Lamont & 36.61 & -97.49 & no & yes & no \\
\hline GAPP & SGP & E 15 Ringwood & 36.43 & -98.28 & no & yes & no \\
\hline GAPP & SGP & E 16 Vici & 36.06 & -99.13 & no & yes & no \\
\hline GAPP & SGP & E 18 Morris & 35.69 & -95.86 & no & yes & no \\
\hline GAPP & SGP & E 19 El_Reno & 35.55 & -98.02 & no & yes & no \\
\hline GAPP & SGP & E 20 Meeker & 35.56 & -96.99 & no & yes & no \\
\hline GAPP & SGP & E 21 Okmulgee & 35.62 & -96.06 & no & yes & no \\
\hline GAPP & SGP & E 22 Cordell & 35.35 & -98.98 & no & yes & no \\
\hline GAPP & SGP & E 24 Cyril & 34.88 & -98.20 & no & yes & no \\
\hline GAPP & SGP & E 26 Cement & 34.96 & -98.08 & no & yes & no \\
\hline GAPP & SGP & E 27 Earlsboro & 35.27 & -96.74 & no & yes & no \\
\hline MDB & Tumbarumba & Tumbarumba & -35.65 & 148.15 & no & yes & yes \\
\hline
\end{tabular}

968 Table 1. CEOP stations with sufficient in situ LST, LH, SH, or GH observations for validation

969 (CSE=Continental-Scale Experiment). 


\begin{tabular}{|c|c|c|c|c|c|c|}
\hline \multirow[t]{2}{*}{ Perturbation } & \multirow{2}{*}{$\begin{array}{l}\text { Additive (A) } \\
\text { or } \\
\text { multiplicative } \\
\text { (M)? }\end{array}$} & \multirow[t]{2}{*}{$\begin{array}{l}\text { Standard } \\
\text { deviation }\end{array}$} & \multirow{2}{*}{$\begin{array}{l}\text { AR(1) time } \\
\text { series } \\
\text { correlation } \\
\text { scale }\end{array}$} & \multicolumn{3}{|c|}{$\begin{array}{l}\text { Cross-correlation } \\
\text { with perturbations in }\end{array}$} \\
\hline & & & & $\mathrm{T} 2 \mathrm{M}$ & SW & LW \\
\hline $\begin{array}{l}\text { Air temperature } \\
\text { (T2M) }\end{array}$ & A & $1 \mathrm{~K}$ & 1 day & $\mathrm{n} / \mathrm{a}$ & 0.4 & 0.4 \\
\hline $\begin{array}{l}\text { Downward shortwave } \\
\text { (SW) }\end{array}$ & $\mathrm{M}$ & 0.3 & 1 day & 0.4 & $\mathrm{n} / \mathrm{a}$ & -0.6 \\
\hline $\begin{array}{l}\text { Downward longwave } \\
\text { (LW) }\end{array}$ & A & $20 \mathrm{~W} \mathrm{~m}^{-2}$ & 1 day & 0.4 & -0.6 & $\mathrm{n} / \mathrm{a}$ \\
\hline $\begin{array}{l}\text { Soil temperature } \\
\text { prognostic variables } \\
\text { (Catchment: TSURF; } \\
\text { Noah: TSOIL1) }\end{array}$ & A & $0.2 \mathrm{~K}$ & $12 \mathrm{~h}$ & 0 & 0 & 0 \\
\hline
\end{tabular}

971 Table 2. Parameters for perturbations to meteorological forcing inputs and model prognostic 972 variables. 


\begin{tabular}{|c|c|c|c|c|c|c|c|c|c|c|c|c|c|c|c|c|c|c|c|}
\hline \multirow{4}{*}{ 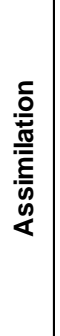 } & \multirow{4}{*}{ 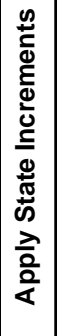 } & \multirow{4}{*}{ 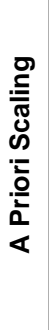 } & \multirow{4}{*}{ 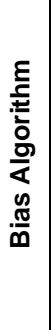 } & \multicolumn{8}{|c|}{ CLSM } & \multicolumn{8}{|c|}{ Noah } \\
\hline & & & & \multicolumn{4}{|c|}{ Anomaly R } & \multicolumn{4}{|c|}{ RMSE } & \multicolumn{4}{|c|}{ Anomaly $\mathbf{R}$} & \multicolumn{4}{|c|}{ RMSE } \\
\hline & & & & LST & LH & SH & GH & LST & LH & SH & GH & LST & LH & SH & GH & LST & LH & SH & GH \\
\hline & & & & {$[-]$} & \multicolumn{3}{|c|}{$[-]$} & {$[\mathrm{K}]$} & \multicolumn{3}{|c|}{$\left[\mathrm{W} \mathrm{m}^{-2}\right]$} & {$[-]$} & \multicolumn{3}{|c|}{$[-]$} & {$[\mathrm{K}]$} & \multicolumn{3}{|c|}{$\left[\mathrm{W} \mathrm{m}^{-2}\right]$} \\
\hline no & $\mathrm{n} / \mathrm{a}$ & $n / a$ & $n / a$ & 0.61 & 0.31 & 0.21 & 0.25 & 4.9 & 54 & 67 & 54 & 0.62 & 0.26 & 0.12 & 0.24 & 5.6 & 50 & 62 & 50 \\
\hline yes & yes & so & bo & 0.63 & 0.31 & 0.21 & 0.25 & 4.7 & 54 & 67 & 54 & 0.66 & 0.27 & 0.14 & 0.14 & 5.1 & 50 & 61 & 61 \\
\hline yes & yes & so & b1 & 0.64 & 0.31 & 0.21 & 0.26 & 4.6 & 54 & 67 & 53 & 0.64 & 0.28 & 0.14 & 0.08 & 5.2 & 50 & 62 & 81 \\
\hline yes & yes & so & b3 & 0.66 & 0.31 & 0.21 & 0.26 & 4.4 & 54 & 68 & 54 & 0.65 & \begin{tabular}{|l|} 
\\
0.28
\end{tabular} & 0.14 & 0.08 & 5.1 & 50 & 62 & 84 \\
\hline yes & yes & so & b5 & 0.66 & 0.31 & 0.21 & 0.25 & 4.4 & 54 & 68 & 54 & 0.65 & 0.27 & 0.14 & 0.08 & 5.1 & 50 & 62 & 84 \\
\hline yes & yes & so & b8 & 0.67 & 0.31 & 0.21 & 0.25 & 4.2 & 54 & 68 & 54 & $0.67 \mid$ & \begin{tabular}{|l|} 
\\
0.28
\end{tabular} & 0.14 & 0.11 & 5.0 & 50 & 62 & 78 \\
\hline yes & no & so & b1 & 0.63 & 0.31 & 0.21 & 0.26 & 4.7 & 54 & 67 & 53 & 0.63 & \begin{tabular}{|l|} 
\\
0.28
\end{tabular} & 0.13 & 0.10 & 5.3 & 50 & 63 & 77 \\
\hline yes & no & so & b3 & 0.65 & 0.31 & 0.21 & 0.26 & 4.4 & 54 & 68 & 54 & 0.64 & 0.28 & 0.13 & 0.09 & 5.2 & 50 & 63 & 78 \\
\hline yes & no & so & b5 & 0.66 & 0.31 & 0.21 & 0.26 & 4.4 & 54 & 68 & 54 & 0.65 & 0.28 & 0.13 & 0.09 & 5.1 & 50 & 63 & 78 \\
\hline yes & no & so & b8 & 0.66 & 0.31 & 0.21 & 0.25 & 4.3 & 54 & 68 & 54 & 0.66 & 0.28 & 0.13 & 0.14 & 5.0 & 50 & 62 & 73 \\
\hline yes & yes & s1 & bo & 0.63 & 0.31 & 0.21 & 0.25 & 4.8 & 54 & 67 & 54 & 0.66 & 0.26 & 0.13 & 0.20 & 5.3 & 50 & 61 & 53 \\
\hline yes & yes & s1 & b1 & 0.65 & 0.31 & 0.21 & 0.25 & 4.6 & 54 & 67 & 54 & 0.66 & 0.26 & 0.13 & 0.15 & 5.2 & 50 & 62 & 58 \\
\hline yes & yes & s1 & b3 & 0.67 & 0.31 & 0.21 & 0.25 & 4.5 & 54 & 67 & 54 & 0.66 & 0.26 & 0.13 & 0.15 & 5.2 & 50 & 62 & 58 \\
\hline yes & yes & s1 & b5 & 0.67 & 0.31 & 0.21 & 0.25 & 4.5 & 54 & 67 & 54 & 0.66 & 0.26 & 0.13 & 0.15 & 5.2 & 50 & 62 & 58 \\
\hline yes & yes & s1 & b8 & 0.66 & 0.31 & 0.21 & 0.25 & 4.6 & 54 & 67 & 54 & $0.67 \mid$ & \begin{tabular}{|l|} 
\\
\end{tabular} & 0.13 & 0.17 & 5.2 & 49 & 61 & 56 \\
\hline yes & no & s1 & b1 & 0.64 & 0.31 & 0.21 & 0.25 & 4.6 & 54 & 67 & 54 & 0.65 & 0.26 & 0.13 & 0.15 & 5.2 & 50 & 62 & 57 \\
\hline yes & no & s1 & b3 & 0.66 & 0.31 & 0.21 & 0.25 & 4.6 & 54 & 67 & 54 & 0.65 & \begin{tabular}{|l|} 
\\
0.27
\end{tabular} & 0.13 & 0.15 & 5.2 & 50 & 62 & 57 \\
\hline yes & no & s1 & b5 & 0.66 & 0.31 & 0.21 & 0.25 & 4.5 & 54 & 67 & 54 & 0.66 & 0.27 & 0.13 & 0.15 & 5.2 & 50 & 62 & 57 \\
\hline yes & no & s1 & b8 & 0.65 & 0.31 & 0.21 & 0.25 & 4.6 & 54 & 67 & 54 & 0.66 & \begin{tabular}{|l|} 
\\
0.27
\end{tabular} & 0.12 & 0.17 & 5.2 & 50 & 62 & 55 \\
\hline
\end{tabular}

974 Table 3. Skill of model and assimilation integrations versus CEOP in situ observations.

975 Integrations shown in bold face are those discussed in the main text. Anomaly R for LST from

976 ISCCP is 0.52 , RMSE is $7.6 \mathrm{~K}$. 


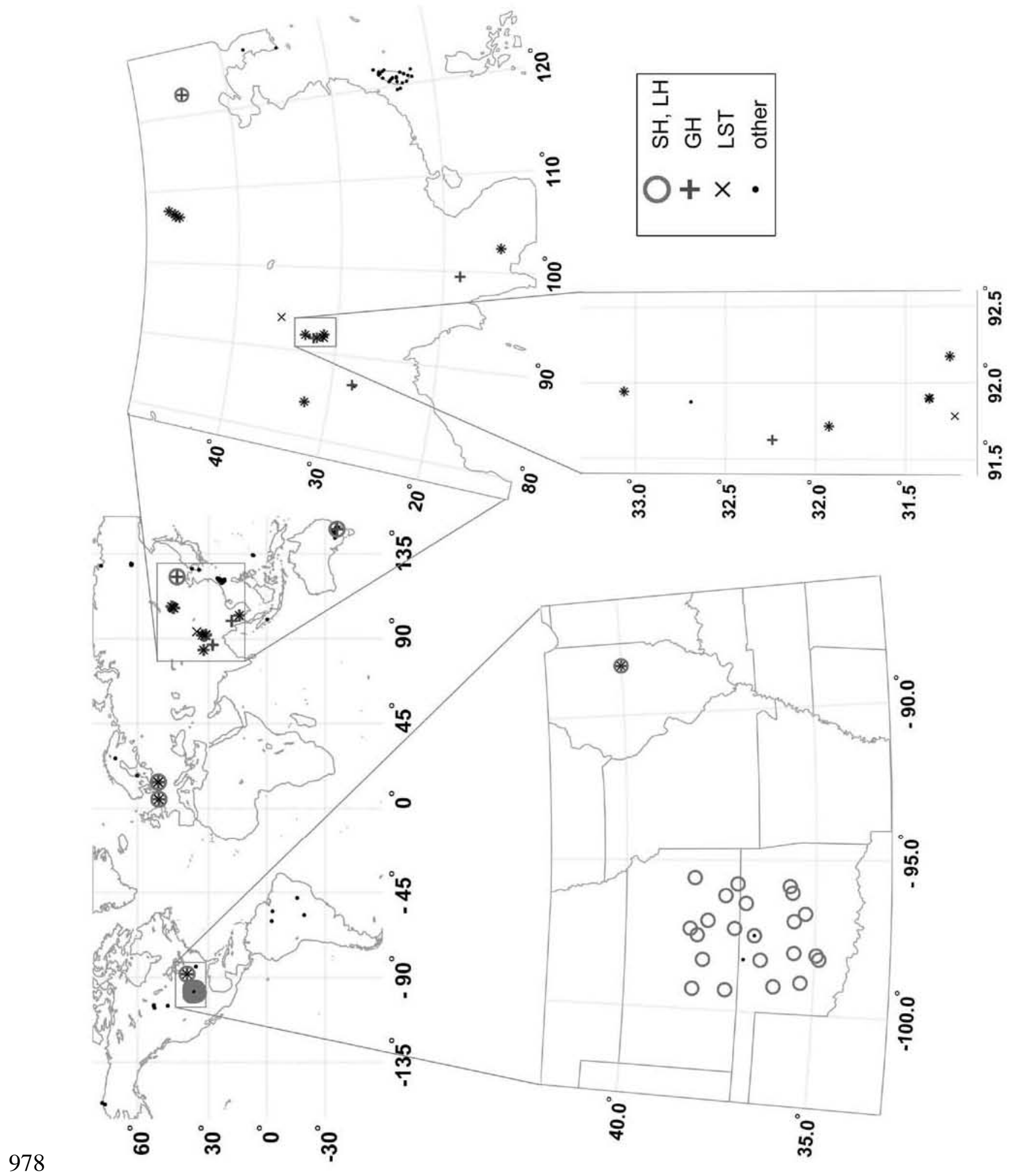

979 Fig. 1. Location of CEOP stations. Stations suitable for validation are indicated with circles

980 (SH, LH, 30 stations), plus signs (GH, 20 stations), and crosses (LST, 19 stations). 


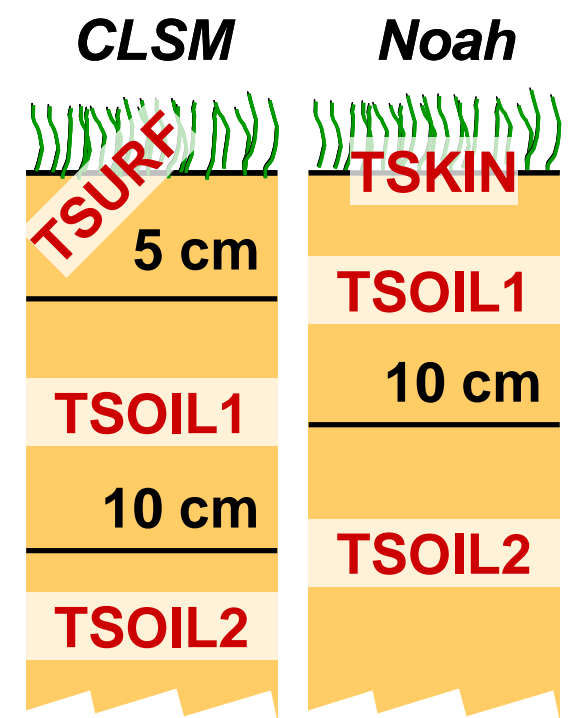

981

982 Fig. 2. LST is described in (left) CLSM with a prognostic variable ("TSURF") and in (right)

983 Noah with a diagnostic variable ("TSKIN"). LST increments are applied to "TSURF" in CLSM

984 and to "TSOIL1" in Noah (section 4.b.).

985 

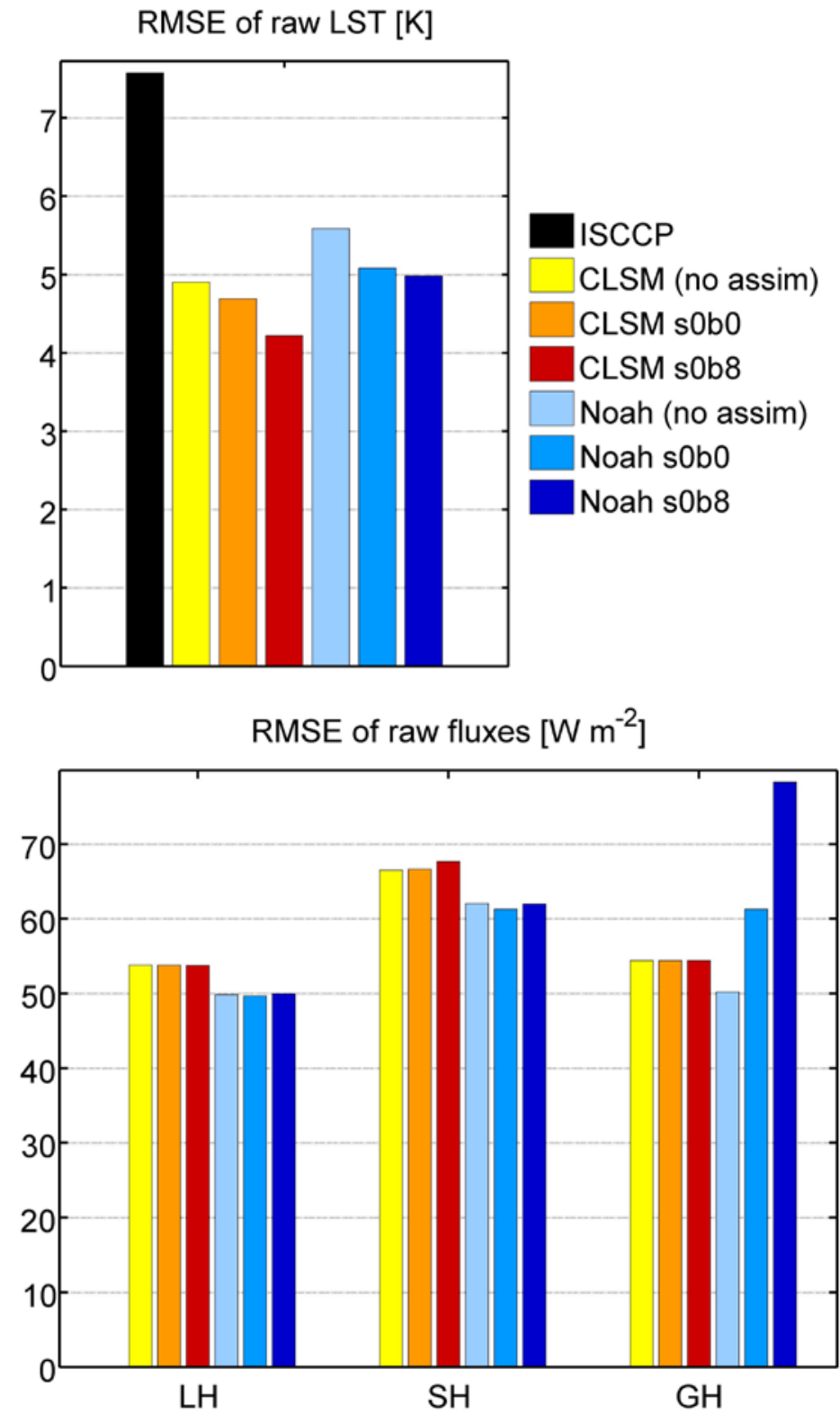

988

989 Fig. 3. RMSE versus CEOP in situ observations for (top) LST and (bottom) flux estimates from

990 ISCCP retrievals (LST only), model integrations, and select assimilation integrations without a

991 priori scaling.

992 


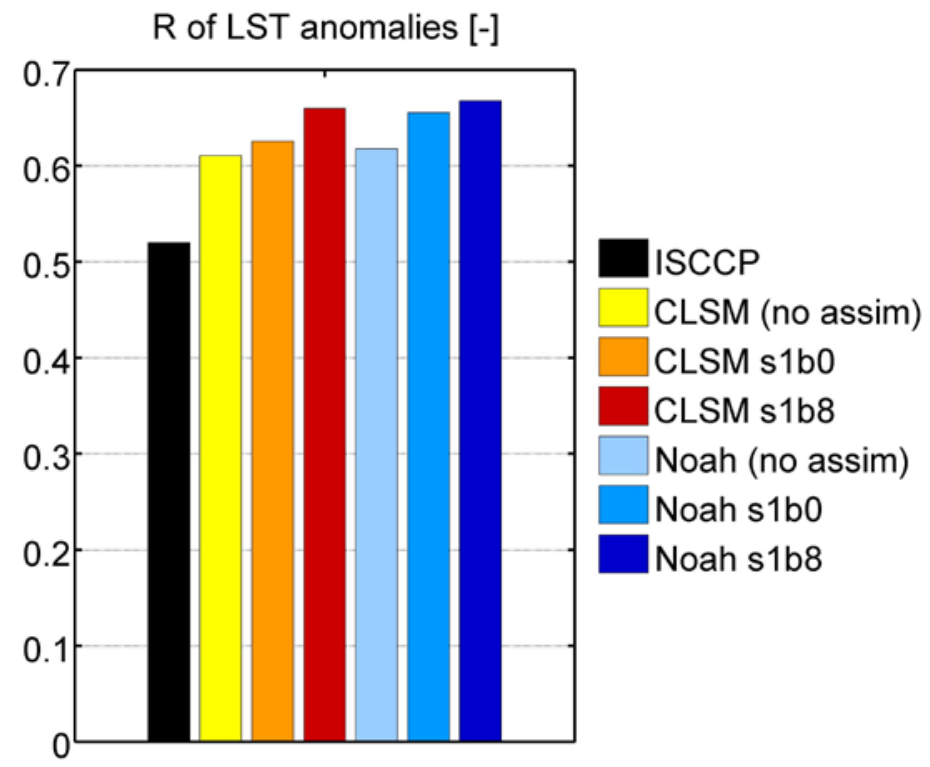

994 Fig. 4. R versus CEOP in situ observations for LST anomalies from ISCCP retrievals, model 995 integrations, and select assimilation integrations with a priori scaling.

996 

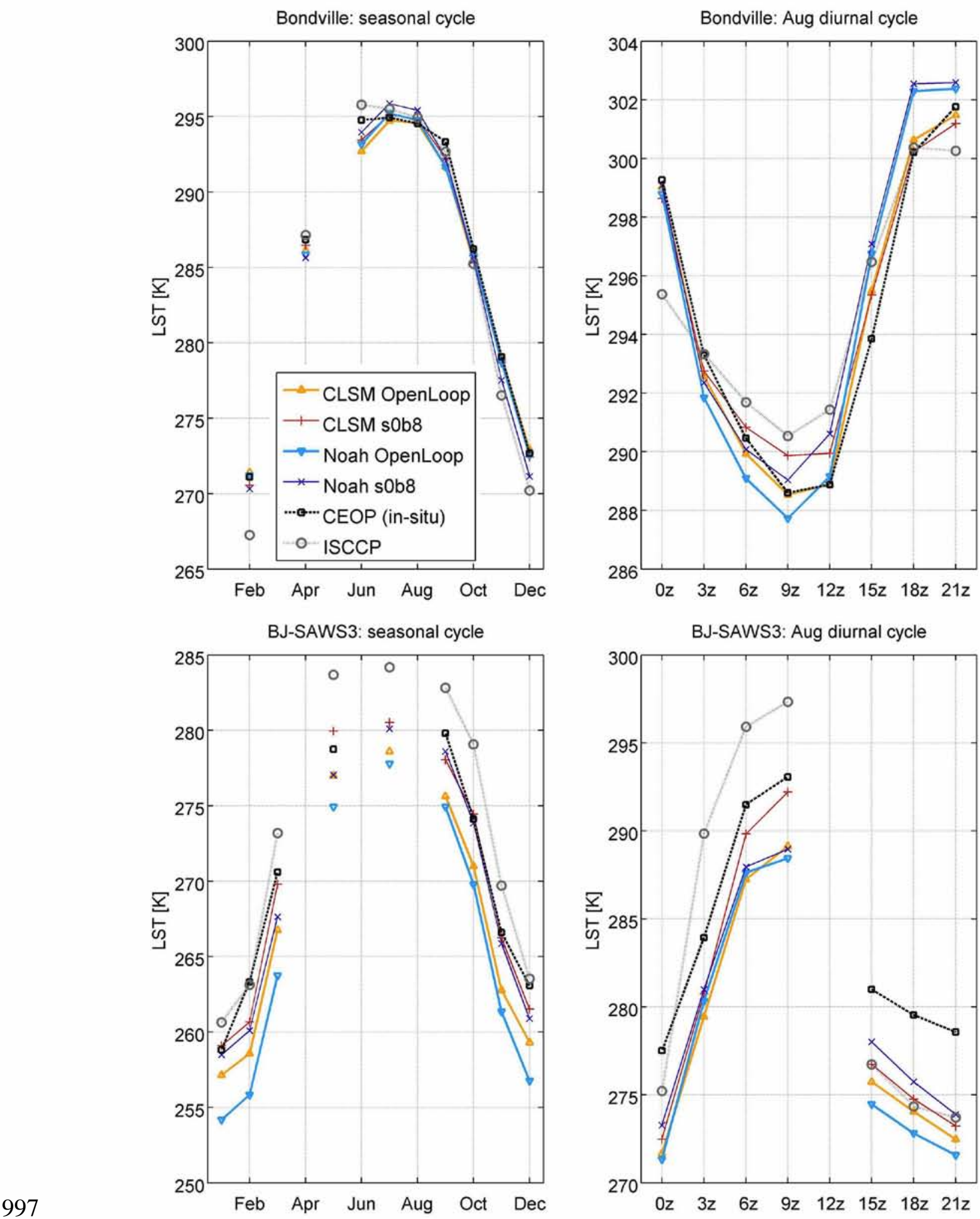

998 Fig. 5. LST (left) annual seasonal and (right) August diurnal cycle at (top) Bondville and

999 (bottom) BJ-SAWS3 for CEOP, ISCCP, model, and assimilation data. 


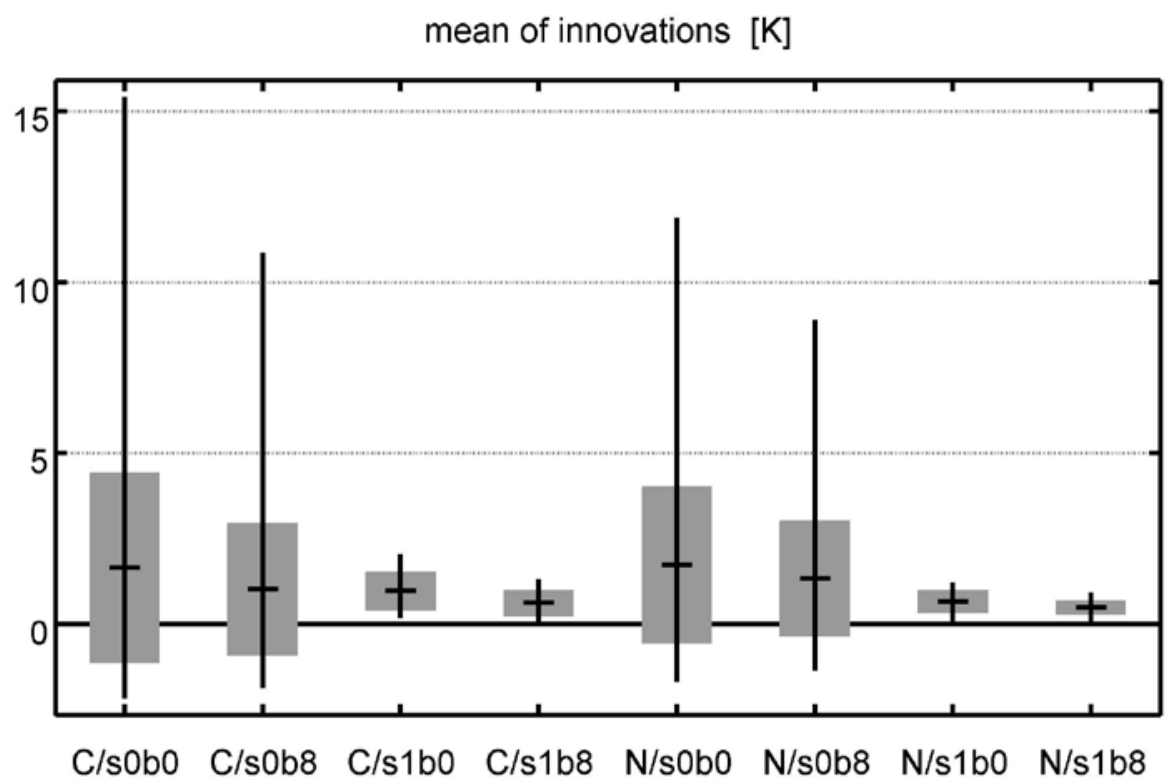

std-dev of normalized innovations [-]

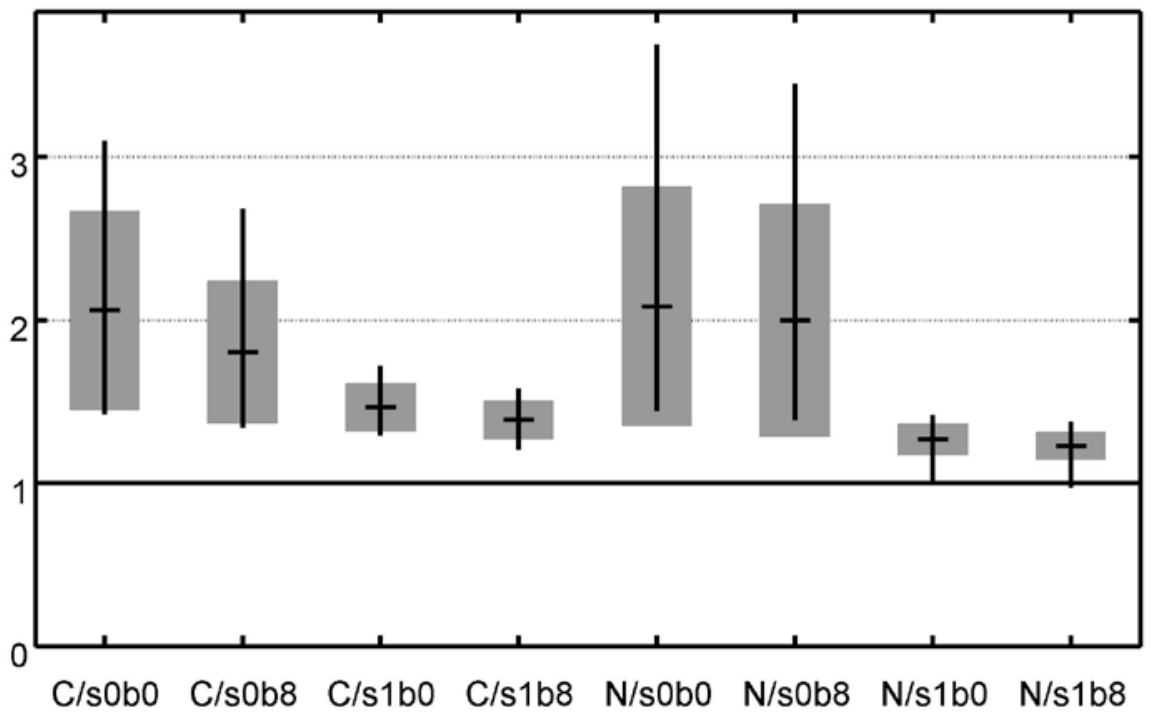

1001 Fig. 6. (Top) Mean of innovations [K] and (bottom) standard deviation of normalized

1002 innovations [dimensionless] for (C) Catchment and (N) Noah assimilation integrations. The box

1003 plots indicate the average, standard deviation, minimum and maximum of the respective

1004 innovations diagnostic across the stations listed in Table 1.

1005 

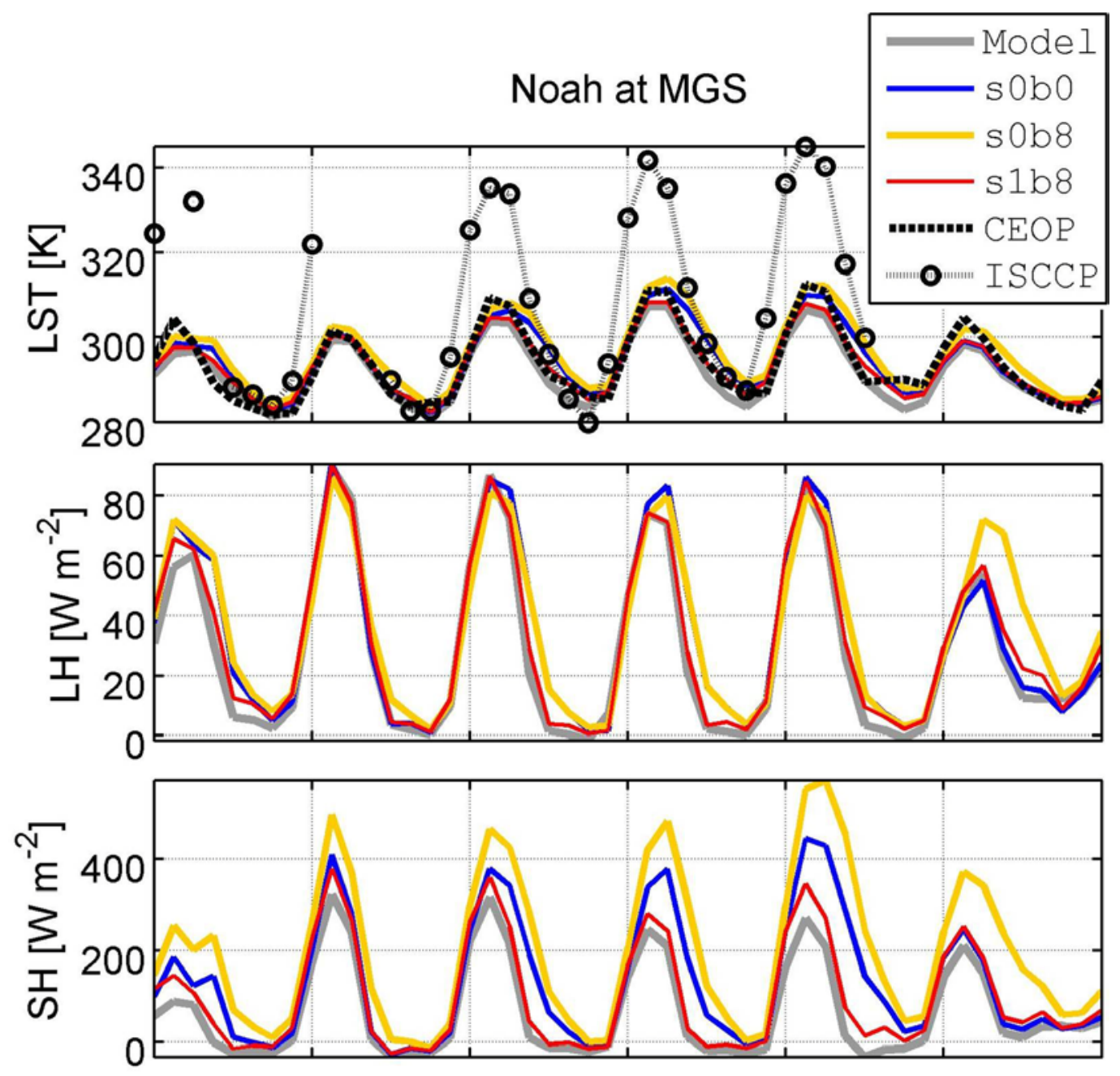

1006

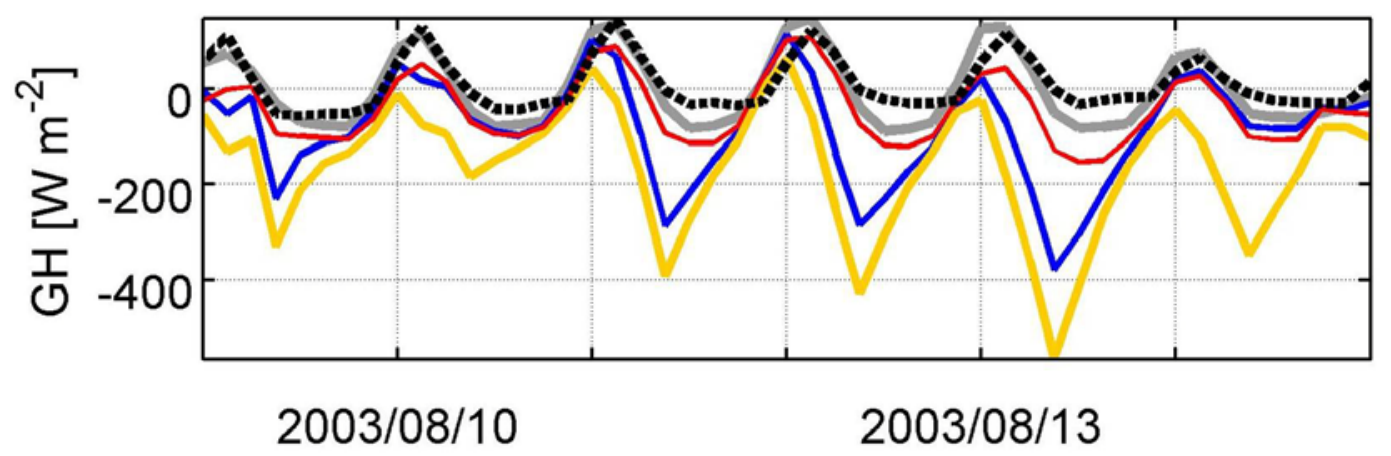

1007 Fig. 7. (Top) LST, (upper middle) LH, (lower middle) SH, and (bottom) GH for Noah 1008 integrations, ISCCP retrievals, and CEOP observations at the MGS station. 